\title{
https://doi.org/10.46291/ISPECIJSSHvol4iss5pp449-475
}

\section{Kutadgu Bilig’in Transliterasyonuna Dair Bazı Meseleler (Mısır Nüshası)}

\section{Melek ÇUBUKCU}

Çukurova Üniversitesi, Fen Edebiyat Fakültesi, Türk Dili ve Edebiyatı Bölümü, melek0134@ gmail.com , Orcid : 0000-0001-6821-2681

\section{ÖZET}

Bu çalışmada, Kutadgu Bilig’in üç değerli nüshasından biri olan Arap harfli Mısır nüshası hakkında birtakım yazım meselelerine değinilecektir. Çalışmada Kutadgu Bilig’in Mısır nüshasından hareketle, Reşit Rahmeti Arat'ın okuyuşunda ve tarafımca yapılan okumada ortaya çıkan farklı yazım özellikleri tespit edilecektir. Bu farklılıklar ünlüler ve ünsüzler olarak iki farklı grupta değerlendirilecektir. Bu çalışma için öncelikle, Reşit Rahmeti Arat'ın üç nüshayı da kapsayan metin yayınından Mısır nüshasına ait olan kısımlar çıkarılmış ve Mısır nüshasına özgü bir metin oluşturulmuştur. Bunun için gerek metinden gerekse dipnotlardan faydalanılmıştır. İkinci okuma ise Arat'tan tamamen bağımsız olarak, tarafımca, yalnızca nüsha dikkate alınarak yapılmıştır. Verilen örneklerden ilki Reşit Rahmeti Arat'ın Kutadgu Bilig Metin yayınından alınmıştır. İkinci kısımdaki örnek ise kelimenin yazımının uygun olduğu düşünülen biçimidir. Verilen örneklerin yanına sırasıyla, kelimenin ait oldugu nüsha, sayfa sayısı, beyit ve satır nurmarası eklenmiştir. Ünlülerden /a/, /e/, /1/, /i/, /o/, /u/ ve /ü/ ile ilgili örnekler tespit edilmiş olup, ünsüzler için ise yalnızca /d/ ve /z/ ünsüzleri ile ilgili örnekler bulunabilmiştir. $\mathrm{Bu}$ çalışma Kutadgu Bilig’in yalnızca bin beytini içermekte olup, ortaya çıkan örnek sayısının, nüshanın tamamına ait genelleyici bir yorum yapma şansını bize tanıdığını düşünmekteyim.

Anahtar Kelimeler: Kutadgu Bilig, Mısır Nüshası, Reşit Rahmeti Arat, Transliterasyon.

\section{Some Issues Regarding the Translitteration of Kutadgu Bilig (Egypt Generation)}

\begin{abstract}
In this study, some writing issues about the Egyptian copy with Arabic letters, one of the three valuable copies of Kutadgu Bilig, will be discussed. In this study, based on the Egyptian copy of Kutadgu Bilig, different spelling features that appear in the reading of Reşit Rahmeti Arat and the reading done by us will be determined. These differences will be evaluated in two different groups as vowels and consonants. For this study, firstly, the parts belonging to the Egyptian copy were removed from the text publication of Reşit Rahmeti Arat, which included three copies, and a text specific to the Egyptian copy was created. For this, both the text and footnotes have been used. The second reading was made by me, completely independent of Arat, considering only the copy.The first example given was taken from the Kutadgu Bilig Text publication of Reşit Rahmeti Arat. The example in the second part is the form of the word that is thought to be spelling. Next to the examples given, the copy of the word, the number of pages, couplets and line notation are added respectively.Examples of vowels / a /, / e /, / 1/, / i /, / o /, / u / and / ü / have been identified, and only examples of consonants / $\mathrm{d} /$ and / $\mathrm{z} /$ consonants could be found. This study contains only one thousand couplets of Kutadgu Bilig, and I think that the resulting number of samples gives us the chance to make a generalist comment on the whole copy.
\end{abstract}

Keywords: Kutadgu Bilig, Egyptian Copy, Reşit Rahmeti Arat, Transliteration. 


\section{GíRIŞ}

\section{1. Kutadgu Bilig'in Mısır (Kahire) Nüshası}

Kutadgu Bilig'in Arap harfli Mısır nüshası'nın, 14. yüzyılda istinsah edildiği tahmin edilir.

Nüsha, 1896 y1lında Kahire'de, Hidiv Kütüphanesinin müdürü Alman bilginlerden Moritz tarafından bulunmuştur. Kütüphanenin düzenlemesi esnasında bodrum kata atılmış olan dağınık kitap ve sayfa yığınları gözden geçirilirken, Kutadgu Bilig’e ait parçalar tespit edilmiş, bunlar toplanarak bir araya getirilmiş ve böylece nüsha kaybolmaktan kurtarılmıştır. Açık ve okunaklı olan nüshanın başında ve ortasındaki bazı sayfalar rutubetin etkisiyle okunamaz duruma gelmiştir; fakat buna rağmen metnin büyük kısmı iyi durumdadır. Nüshanın 16 (73-454), 24 (587-646), 36 (836-957), 72 (1504-1562), 272 (4579-4610), 374 (6245-6303) ve 392. (6632-6645) sayfalarından sonra gelen beyitlerde eksiklik vardır. Bu durumun metnin, ilgili sayfalarının kaybolmasıyla ilgili olduğu düşünülür.

Özbekistan Ebu Reyhan El-Biruni Yazma Eserler Kütüphanesinde bu nüshadan 1897 yılında istinsah edilmiş 4 cilt hâlinde bir nüsha daha vardır. Kütüphane Müdürü Moritz, Radloff'un isteği üzerine bir Arap filolog ve hattata bu yeni nüshayı hazırlatmıştır (Üşenmez, 2013).

Hâlâ Mısır'da bulunan nüsha, Türk Dil Kurumu tarafından 1943 yılında tıpkıbasım olarak yayımlanmıştır. 2014 yılında Emek Üşenmez ve ErdemUçar tarafından baskıya hazırlanan bu nüshanın da tıpkıbasımı yapılmıştır. ( Üşenmez ve Uçar, 2014).

\section{BULGULAR}

\section{1. Ünlüler}

\section{1. 1. /a/ Ünlüsü}

321 örnekte /a/ ünlüsünün yazımında farklılık tespit edilmiştir.

$$
\begin{aligned}
& \text { 'ạlẹm / 'alem(M117, } \\
& \text { 2227-17) } \\
& \text { 'ạlẹm / 'alẹm(M130, } \\
& \text { 2418-17) } \\
& \text { 'ạța / 'aṭa(M90, 1829-13) }
\end{aligned}
$$

$$
\text { baġırḳa / bạgı̀rḳa(M99, }
$$$$
\text { 1947-8) }
$$$$
\text { baġırsak / bạgirsak(M111, }
$$
2123-2;116, 2204-9;118, $2235-8 ; 134,2473-15 ; 138$, 2529-12;139, 2543-13;81, 1687-12;91, 1838-8;91, 1838-9;92, 1852-8; 99, 1944-4; 76, 1615-9) baġırsak / bạg̣̣ırsaḳ(M113, 2160-9; 94, 1881-7; 99, 1942-1; 99, 1943-3) bag்ırsaḳ / bạğıูırsaḳ(M111, 2123-2; 99, 1945-5; 99, 1946-7) bag̈ırsakka bạgırsaḳka(M84, 1728-4) baġırsakka bạğırısakka(M99, 1943-2) bag̈ırsaḳlık bạgırsaḳlıḳ(M99, 1945-5) bağırsaḳlıḳı bạğğrsaḳliḳ1(M107, 207314) 
bağırsaḳlıḳın

bạgı̀rsaḳlıḳın(M77, 1634-

14)

baġırsaḳlıḳın

bạgırsaḳlı̣kın(M131,

2432-16)

baġırsaḳlıḳın

bạgııırsaḳlıı̣ın(M99, 1944-

4)

baġırsak-lıḳı / bạgı̀ırsak-

liḳın(M94, 1878-9)

baġırsaknı

bạgirsaknı(M99, 1946-7;

99, 1947-8)

bağışla / bạgiş̧la(M106, 2053-9)

bạg̣̣ırsaḳ / bạgıırsaḳ(M138, 2529-12)

bak / bạk(M104, 2020-5; 88, 1792-6)

baḳa / baka(M110, 2112-

6; 112, 2149-14)

baḳar / bạkar(M92, 1857-

14)

baḳıp / bạkıp(M96, 1904-

4)

baḳır / bạḳır(M97, 1916-

3)

baḳışı / bạḳış1(M92,

1855-12)

baḳsa / bạksa(M108, 2084-8;77, 1632-12;89, 1806-14; 92, 1856-13;95, 1896-11;95, 1897-12;96, 1902-1)

baḳtı / bạktı(M85, 175213)

baldu / bạldu(M112, 2141-5; 112, 2143-7; 84, 1736-12)

bar / bạr(M85, 1749-10)

barça / bạrça(M100, 1958-3;101, 1984-17;102, 1987-2;106, 2047-2;106, 2048-3;107, 2076-17;109, 2107-17;115, 2191$11 ; 117, \quad 2219-8 ; 120$, 2261-3;134, 2474-16;135, 2483-7;136, 2502-15;137, 2506-2;139, 2533-4;76,
1615-9;76, 1617-11;78, 1648-13;80, 1670-8;81, 1683-7;81, 1687-12;83, 1716-9;84, 1739-16;86, 1763-8;86, 1768-13;86, 1769-14;87, 1777-6;93, 1873-16;95, 1890-1;98, 1937-13)

bard1 / bard1(M77, 16266; 80, 1671-9; 82, 1693-2; 94, 1885-11)

barg̉ay / bạrg̉ay(M78, 1645-10)

barg்u / bạrg̉u(M85, 1755-

16)

bạrın / barın(M83, 1722-

16)

barır / bạrır(M86, 1763-8)

barış / bạrış(M136, 24957)

barsa / bạrsa(M78, 164914; 97, 1924-13)

basa / basa(M128, 238616; 139, 2538-7; 90, 1821-5; 95, 1898-13)

basar / bạsar(M104, 202814)

basg்u / bạsg்u(M125, 2343-17)

basġuçı / bạsg̉uçı(M131, 2425-8)

basg̉uḳa / bạsg̉uka(M127, 2362-4)

basımç1 / bạsımçı(M126, 2348-6; 84, 1737-14)

basınç / bạsınç(M86, 1771-16)

basinur / bạsınur(M127, 2268-13)

basit (Mt)1̄ / bạsit(Mt)1̄ (M127, 2369-14)

bastı / bạstı(M131, 2425-

8)

basut / bạsut(M136, 250215)

baş / bạş(M112, 2147-12; 113, 2155-4; 76, 1618-12; 94, 1883-9) başç1 / bạşçı (M111, 2124-3; 124, 2320-16; 130, 2413-12)

başç1sı / bạşçısı(M106, 2048-3; 120, 2270-13; 124, 2329-15; 125, 23311 ; 139, 2540-9)

başı / bạşı(M , 15988;100, 1967-13;102, 1992-7;105, 2040-10;106, 2045-1;106, 2047-2;108, 2089-14;113, 2154-3;113, 2166-16;115, 219616;116, 2201-6;121, 2275-3;122, 2300-15;129, 2394-6;133, 2457-14;137, 2510-6;137, 2516-12)bạş1 / baş1(M87, 1781-11;90, 1830-15;94, 1881-7;97, 1914-1;99, 1945-5)

başın / bạşın(M102, 19894; 126, 2352-10; 137, 2515-11; 137, 2518-15)

başında / bạşında(M120, 2271-14; 127, 2367-11; 88, 1798-13; 99, 1955-16) başı1n / bạşı1n(M137, 251410)

başı̄a / bạşı̄ina(M123, 2309-11)

başınnı / bạşınnı(M137, 2514-10)

başḳa / bạşḳa(M130, 2413-12; 136, 2492-5)

başladı / bạşladı(M99, 1952-13)

başlag̉u / bạşlag̉u(M136, 2497-8)

başlamak / bạşlamak (M120, 2272-15)

başlamaḳı

bạşlamaḳ1(M112, 214712)

başlap / bạşlap(M139, 2537-6)

başlar / bạşlar(M100, 1967-13;105, 204414;120, 2266-9;121, 2275-3;122, 2296-11;125, 2341-14;126, 2346-3;130, 
$2410-8 ; 130,2414-13 ; 130$, 2418-17;138, $\quad 10$. başl1k;138, 2527-9;138, 2529-12)

başlasa / bạşlasa(M120, 2267-10;124, 2320$16 ; 130, \quad 2410-9 ; 135$, 2485-10;139, 2536-5;97, 1924-13)

başlı̀ / bạşılı̀g(M122, 2301-16; 122, 2301-16) başsız / bạşsı (M123, ; $125,2333-3 ; 125,2333-4)$ başta / bạşta(M91, 18366)

bayat / bạat(M101, 1978-10;101, 1980$12 ; 101, \quad 1983-15 ; 103$, 2007-7;86, 1766-5 /6;88, 1797-12;88, 1799-14;88, 1800-15;89, 1811-9;89, 1813-12;90, 1818-2;91, 1838-8;91, 1838-9;93, 1873-16;94, 1877-2;97, 1922-11;98, 1933-7;98, 1934-8;98, 1940-16)

bayatḳa / bạyatḳa(M113, 2158-7; 81, 1686-10;87, 1782-12)

bạytı $\dot{\mathrm{g}}$ / baytı̇ $\dot{\mathrm{g}}(\mathrm{M} 105$, 2046-15)

hal / hạl(M120, 2261-3)

halk / hạlḳ(M79, 166114)

hạlḳkạa / halḳkạ(M132, 2438-8)

ḳaçan / ḳạçan(M109, 2097-6; 109, 2103-12; 129, 2400-13)

ḳaçar / ḳạçar(M103, 2012-13; 109, 2104-14; 119 , 2255-14; 122, 22905)

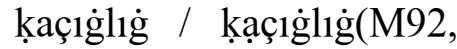
1858-15)

ḳaçsa / kạ̧̧̧sa(M128, 2388-18; 129, 2390-2; 129, 2395-7)

kaḍgu ～/ kạ̣̣gu(M112, 2148-13) ḳalı / kạlı(M102, 19872;102, 1996-13;103, 2011-11;104, 202915;106, 2048-3;106, 2053-9;108, 2087-11;110, 2108-1;110, 2119-15;125, 2341-14;127, 2362-4;128, 2373-1;128, 2388-18;129, $2390-2 ; 129, \quad 2403-7 ; 131$, 2420-2;131, 2421-3;136, 2502-16;139, 2537-6;139, 2540-9;76, 1610-4;76, 1611-5;89, 1810-8;96, 1910-12;97, 1919-7; 87, 1776-5)

kalın / kạlın(M121, 22764; 125, 2336-7; 76, 1618$12 ; 82,1696-7$ )

ḳalın / ḳạlın(M114, 217812)

kalın / kalın(M77, 16221)

kalır / kạalır(M77, 1623-3)

kalır / kẹlir(M136, 2502-

16)

kamçılı̀

kạmç11ı̀g(M126, 2354-12)

kamug / kạmuġ(M100, 1965-11;102, 199916;103, 2003-3;103, 2004-4;103, 2006-6; 103, 2008-8;103， 2008-8;103, 2009-9;107, 2074-15;109, 2106-16;115, 2185-4;116, 2202-7;119, 2252-9;119, 2254-13;119, 225514;133, 2451-2;134, 2468-10;134, 2472$14 ; 135, \quad 2482-7 ; \quad 135$, 2484-9;138, 2523-4;138, 2531-15;76, 1609-3;78, $1650-16 ; 81, \quad 1680-4 ; 82$, 1695-4;83, 1722-16;85, 1752-13;86, 1758-2;86, 1765-10;86, 1769-14;86, 1771-16;87, 1785-15;92, 1851-7;92, 1852-8;92, 1857-14;95, 1897-12;99, 1942-1) kamug்-da / kạamugda(M105, 2037-6; 134, 2475-17)

kamugkka

kamuġka(M102, 1996-13; 133, 2449-5; 82, 1707-17; 92, 1854-10)

kamuġnı kạmug̉nı(M130, 2409-7) ḳapg் / kạpgì1(M116, 2202-7; 89, 1813-12)

kapug / kạpugig(M138, 10. başlık;138, 2527-9;138, 2529-12;139, 2535-3;139, 2536-5;139, 2540-9;76, 1607-1;78, 1643-8;89, 1811-9)

kapuġda / ḳapuggda(M138, 2530-13; 138, 2530-14; $139,2538-7$; 139, 2548-7) kapuggdaḳ1

kạpuğdaḳ1(M86, 1768-13) kara / kara(M108, 20804;108, 2082-6;109, 2097$6 ; 109, \quad 2107-17 ; \quad 119$, 2257-16; 76, 1618-12)

karaḳ / kạraḳ(M127, 2268-13)

ḳaraḳçı / ḳạraḳçı(M84, 1737-14)

karalı / kạalı(M108, 2080-4)

ḳarayḳu / ḳạạḳu(M91, 1840-11)

ḳarası / kạası(M108, 2080-4; 120, 2260-2)

kar1 / karı(M93, 1868-10; 93, 1870-13)

ḳarımaz / kạạmaz(M78, 1639-3)

ḳarır / ḳạrır(M84, 173612)

ḳarısa / kạrısa (M120, 2263-5)

karısı / kạarısı(M93, 187114)

ḳarışgan / ḳarışġan(M128, 2379-7)

ḳarş1 / ḳạrş1(M139, 25353) 


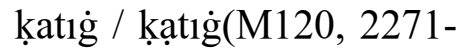
14; 136, 2504-18; 137, 2511-7; 99, 1949-10)

katı̇̉lan / kạtığlan(M113, 2157-6)

katığlan- / ḳạtıglan(M127, 2361-3)

katiğlang்u

ḳạtığlang்u(M126, 2351-9)

ḳatılma / ḳatılma(M119, 2252-10; 119, 2257-16)

katılmaz

kạtılmaz(M119, 2255-14)

ḳatılsa / kạtılsa(M128, 2377-5; 128, 2377-5)

katḳısı / kạtḳısı(M118, 2233-6)

katlıp / ḳatlı̣p(M81, 16826)

kaya / ḳaya(M123, 231315)

ḳaya / ḳạan(M121, 2281-10)

ḳayag / ḳayag்(M84, 1734-10)

ḳayda / ḳayda(M106, 2056-11; 119, 2248-5; 93, 1870-13; 91, 1834-3)

kạyır-ça / ḳaỵ̣r-ça(M83, 1723-17)

ḳayu / ḳayu(M139, 254414)

ḳazar / ḳạar(M84, 173410; 84, 1735-11)

ḳaznaḳ / kạznaḳ(M114, 2178-12)

ḳaznaḳı / ḳąnaḳı(M83, 1719-12)

ma ' ni-si / mạ 'nisi(M87, 1779-8)

mạ 'ni / ma 'ni(M138, 2521-1)

mana / mạya (M93, ; , 1591-1;114, 2176-10;120, 2266-9;120, 2268-11;125, 2335-6;129, 2394-6;131, 2431-15;138, 2527-9;77, 1633-12;88, 1795-9;93, 1873-16;94, 1877-2;98,
1941-17;99, 1942-1;99, 1947-8)

nişạnı / nịşanı(M117, 2224-13; 95, 1894-8)

saçar / sạçar(M122, 2290-

5)

saçıtsa / sạçıtsa(M129, 2396-8)

sak / sạk(M103, 201415;103, 2016-17;104, 2020-5;104, 2025-11;104, 2028-14;104, 202915;117, 2221-10;118, 2236-9;121, 2273-1;126, 2353-11;126, 2357$17 ; 126, \quad 2358-17 ; 135$, 2481-6;135, 2487-13)

saḳal / sạkal(M88, 179813)

saḳçı / sạkçı(M112, 21437; 112, 2143-7; 126, 2345-2)

saḳınç / sạkı̣ıç(M101, 1984-17)

saḳ1-nuk / sạkınuk(M102，1986-1; 109, 2100-9)

saḳlag̉u / sạklag̉u(M112, 2142-6)

saḳlap / sạklap(M125, 2342-16)

saḳlıḳ / sạklı̣(M100, 1960-6;104, 2019-4;104, 2021-6;104, 2022-7;104, 2026-12;115, 2192$12 ; 126,2353-11)$

sak-lıḳ / sạk-lıḳ(M126, 2357-10)

sạḳıuḳ /sạkııuḳ(M115, 2192-12)

salıp / sạlıp(M107, 20699)

sanç / sạnç(M128, 2378-

6)

sançġa / sạnçġa(M124, 2329-15)

sançg்uç1

sạnçguuçı(M124, 2316-1)

sançġuḳa

sạnçgukạa(M126, 2355-13) sançmış / sạnçmış(M127, 2367-10; 129, )

sançmış / sạnçmı̣ş(M125, 2335-6)

sançt1 / sạnçtı(M104, 2026-12; 129, )

saya / sạna(M85, 17422;94, ;128, 2386-16;137, 2513-9)sạna / saya(M83, 1714-7;85, 1743-3;96, 1902-1;96, 1904-4;99, 1944-4)

saran / saran(M80, 16697; 84, 1731-7)

saranḳa / sạrạnḳa(M124, 2325-11)

sav́1 / sạvi1(M80, 1671-9)

taḍu / tạdu(M81, 1682-6; 90, 1828-12)

taḳ1 / tạkı1(M101, 19768;105, 2046-16;110, 2114-9;114, 2176-10;127, 2364-6;131, 2430-14;132, 2439-9;134, 2469-11;138, 2526-8;142, 2578-2;79, 1663-16;80, 1677-17;85, $1745-6 ; 85, \quad 1748-9 ; 90$, 1822-6;91, 1832-1;96, 1903-3)

taḳış / tạkı̣ş̧(M127, 23657)

talu / tạlu(M107, 207516;108, 2081-5;108, 2081-5;114, 2177-11;115, 2184-3;121, 2273-1; 126, 2349-7)

talusı / tạlusı(M116, 2201-5; 133, 2457-14)

tanuk / tạnuḳ(M111, 2129-8; 111, 2129-9; 117, 2216-15; 117, 2216-15; 83, 1713-6)

tanuḳı / tạnuḳı(M105, 2046-15; 119, 2253-11)

tanda / tạnda(M139, 2536-5; 79, 1562-2) tap / tap(M117, 2216-15; 117, 2216-15; 121, 22775; 121, 2277-5; 129, 2395-7) 
tapg்1 / tạpg்1(M77, 163515)

tap1lı̣ / tạp1lı̣̣(M113, 2159-8)

tapın / tạpın(M113, 2158-

7)

tapisız / tạpısız(M76, 1611-5)

taplamaz / tạplamaz(M76, 1610-4)

tapnurı / tạpnurı(M139, 2543-13)

tapug / tạpugig(M135, 2484-9;135, 2490-17;138, 2531-15;139, 2533-4;76, 1607-1;76, 1611-5;78, 1643-8;86, 1769-14;94, 1878-9;94, 1882-8)

tapuġçı / tạpuğçı (M94, 1882-8;130, 2412-11;131, 2422-5;137, 2510-6;86, 1757-1;86, 1757-1)

tapuggdın / tạpugigdın(M78, 1643-8)

tapugilarda

tạpugilarda(M135, 2484-9)

tapugsak

tạpuġsaḳ(M118, 2237-10)

tapundurgiu

tạpundurgud(M85, 1755 16)

taş / tạş(M , 1586-11; 117, 2216-15)

taş1 / tạş1(M117, 22131;117, 2216-15;117, 2216-15;117, 2216-15)

taşı̀ / tạş1 $\dot{g}(M 82,1696-5)$

taşım / tạşım(M78, 1645-

10)

tav́ar / tạvar(M130, 24086;106, 2057-12)

tav́ar / tạvạar(M87, 178616)

topuġçı / tạpuġçı(M85, 1755-16)

yaḍag / yạdagi(M127, 2370-15; 84, 1734-10)

yaụga / yạ̣gaa(M124, 2329-15) yaḍilsa / yạdịlsa(M98, 1928-1)

yaḍilsu / yạdịlsu(M , 1585-10)

yaḍsa / yạdsa(M121, 2277-5)

yag / yạgì(M128, 2387$17 ; \quad 129$, ;103, 201617;104, 2022-7;104, 2025-11;104, 2026-12; $107, \quad 2067-7 ; 107, \quad 2067-$ 7;109, 2098-7;112, 2144$8 ; 122,2289-4 ; 124,2316-$ 1;124, 2326-12;124, 2329-15;126, 2351-9;126, 2352-10;126, 235513;126, 2355-13;126, 2356-14;127, 2364-6;127, 2366-5;127, 2367-10;128, 2388-18;129, 2390-2;129, 2391-3;129, 2395-7;130, 2404-1;97, 1926-15;128, 2384-12)

yag்ıçı / yạğıçı(M123, 2315-17;123, 231517;124, 2316-1;125, 2334-5;127, 2372-17) yaġıda / yạgida(M121, 2283-12;121, 228514;122, 2290-5;123, 2310-2)

yag்1-da / yạgì-da(M126, 2353-11;107, 2067-7)

yağıdın / yạğ 1 dın(M120, 2270-13;122, 2296-11) yạ்ı $\dot{\mathrm{g}}$ / yạġ $\dot{\mathrm{g}}$ (M129, 2396-8;125, 2341-14;126, 2346-3)

yag்ı / yạg̣ 2141-5)

yag்ıg / yạg gug $\dot{g}(M 104$, 2028-14; 125, 2343-17) yag்ıḳa / yạgikạa(M105, 2043-13;108, 2085-9;120, 2269-12;122, 2288-3;125, 2331-1;125, 2341-14;126, 2349-7;126, 2356-14;127, 2369-14;128, 2378-6) yag̉ınçı / yạg 2371-16) yag̉ını / yạginı(M122, 2287-2)

yaġının / yạgg்ının(M127, 2268-13)

yag்in / yạgin(M127, 2359-1)

yag்ıs1 / yạg̣̣ıs1(M99, 1954-15)

yağısın / yạğısın(M121, 2287-16; 122, 2290-5; 128, 2379-7;129, )

yağ1z / yạgiz (M88, 180015;128, 2384-13)

yag்ma / yạgma(M86, 1758-2)

yağudı / yạgudı(M77, 1631-10)

yag்uk / yạguk(M108, 2079-2;108, 2079-3;119, 2250-7)

yaġusa / yạgusa(M105, 2032-1;126, 2349-7;128, 2375-3;128, 2376-4)

yag̉utsa / yạgutsa(M137, 2506-2)

yaḳa / yạkạ(M128, 23775;128, 2377-5)

yakıın / yạkı1n(M119, 2258-17;120, 2259-1;77, 1631-10; 86, 1767-12) yaḳın / yạkı̣n(M119, 2247-4;125, 2341-14;76, 1612-6)

yakmaz / yạkmaz(M115, 2192-12;119, 2250-7;133, 2445-1)

yaḳş1 / yạhşsı(M82, 170110)

yaḳurma

yạkurma(M137, 2509-5)

yalav́aç / yạlav́aç(M127, 2362-4;136, 2495-7) yalġan / yạlġan(M105, 2039-9;105, 2041-11;106, 2060-17;124, 2324$10 ; 137,2508-4)$

yalganında yạlġanında(M105, 204212) 
yana / yạna (M77, 1623$2 ; 103, \quad 2014-15 ; 106$, 2052-8;106, 2053-9;112, 2146-11;120, 2259-1;123, 2312-14;129, ;129, 2396$8 ; 129,2396-9 ; 130,2417-$ $6 ; 136, \quad 2500-13 ; 137$, 2514-10;137, 2518$14 ; 139, \quad 2536-5 ; 139$, 2540-10;76, $\quad 1613-7 ; 77$, $1624-4 ; 80, \quad 1665-2 ; 80$, $1677-17 ; 86, \quad 1762-7 ; 88$, $1801-16 ; 89, \quad 1815-15 ; 91$, 1832-1;95, 1894-8)

yanut / yạnut(M114, 2181-16;120, 2269$12 ; 132, \quad 2435-4 ; 138$, 2528-11;79, 1658-11;80, 1666-4;81， 1688-13;88, 1796-11;90, 1817-1;91, 1835-5;92, 1850-6;94, 1877-2;95, 1892-4;95, 1896-11;96, 1905-6;96, 1911-14;97, 1918-6;98, 1930-4;99, 1948-9)

yanutı / yạnutı(M111, 2129-8)

yạ / yạ̣(M98, 1931-5; 98, 1934-9)

yay1 / yạ̣1(M77, 163515)

yayılsa / yậ1lsa(M100, 1969-15)

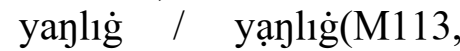
2164-12;114, 2172-5;114, 2173-6;114, 2177-11;118, 2239-12;120, 2260-2;124, 2320-16;130, 2413$12 ; 138,2524-5 ; 87,1787-$ $17 ; 88,1788-1)$

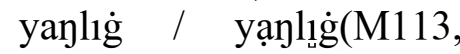
2156-5)

yạluḳ / yậluḳ(M81, 1682-6)

yạ̣luḳ / yayluḳ(M91, 1845-17) yannı / yạ̣nı(M119, 2255-14)

yayzag / yạyzag்(M119, 2255-14) yap / yạp(M128, 2385-15) yapuş / yạpuş(M93, 187013)

yarag் / yạrag்(M108, 2090-15; 127, 2359-1)

yarağçı / yạraġçı(M124, 2316-1)

yaraġ1 / yạraġ1(M127, 2360-2; 92, 1857-14)

yaragilı / yạragil1(M76, 1614-8;76, 1621-17)

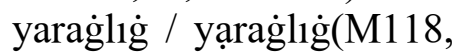
2236-9;130, 2415-4;139, 2544-14;85, 1756-17;86, 1759-13;86, 1766-5/6) yaraġlısı / yạraglısı(M76, 1621-17)

yaraġsız / yạraġsız(M107, 2074-15;115, 2194$14 ; 118, \quad 2236-9 ; 118$, 2241-14;125, 2336-7)

yaraġsız / yạraġsıız(M106, 2060-17)

yaraġsızka

yạrağsıkka(M115, 2192$12 ; 86,1760-4)$

yarag்sızlarìg

yạrağsızları்̀(M136, 2500-13)

yaraġu / yạrag்u(M77, 1628-8)

yaramas / yạramas(M133, 2449-5)

yarap / yạrap(M76, 161914)

yarar / yạrar(M120, 2268-

11)

yaraş / yạraş(M127, 2360-

2)

yaraşġu / yạraşğu(M127, 2360-2)

yaraşı / yạraşı(M107,

2073-14)

yaraşmaz

yạraşmaz(M119, 2249-6)

yaraşsa / yạraşsa (M87, 1780-10; 82, 1702-12; 83, 1709-3)

yaraşt1 / yạraştı(M82, 1695-4) yaraşur / yạraşur (M87, 1778-7;133, 2459-17;82, 1707-17; 82, 1707-17; 83, 1709-3)

yarı / yạrı(M127, 2362-4)

yarı̣ / yorık (M107, 207718)

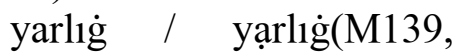
2547-16;86, $1767-$ 12;89, 1810-8)

yarlığ1 / yạrlı่̀1(M89, 1809-7)

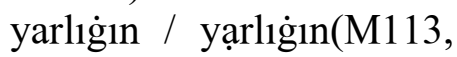
2158-7)

yarudı / yạrudı(M87, 1782-12)

yaruk / yạruḳ(M102, 2000-17;119, 2250-7;135, 2476-11)

yarund 1 / yạrudı(M , 1589-14)

yarutsa / yạrutsa(M , 1601-12)

yaşarg̉u / yạşarğu(M89, 1807-5)

yaşarmış / yạ̧̧armış(M89, 1810-8)

yaşasunı

yạşasunı(M135, 2489-15)

yaş11 / yạş11(M119, 22507;88, 1800-15)

yat $(\mathrm{Mt}) 1$ / yạt(Mt)1(M , 1606-17)

yat / yạt (M128, 2378$6 ; 85,1742-2)$

yatgaak / yạtg̉aḳ(M139, 2533-1)

yatsa / yạtsa(M139, 25331)

yatur / yạtur(M121, 228110;124, 2326-12;142, 2577-1)

yazar / yạzar(M89, 18097;92, 1856-13)

yav́a / yạva(M103, 201314;76, 1611-5)

yav́aşlarḳa

yạv́aşlarḳa(M122, 2299 -

14) 
yav́uz / yạv́uz(M102, $1994-10$; 102 , 1996$13 ; 106, \quad 2060-17 ; 129$, 2400-13)

yav́uzraḳ / yạvuzraḳ(M83, 1717-10)

zamane / zạmane(M101, 1983-16)

\section{1. 2. /e/ Ünlüsü}

294 örnekte /e/ ünlüsünün yazımıla ilgili farklılık tespit edilmiştir.

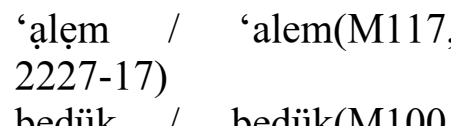

beḍük / bẹ̣ük(M100, 1961-7; 122, 2296-11; 82, 1694-3)

bedüüklükke

bẹ̣üklükke(M118，2233-

6)

bedükrek

bẹ̣ükrek(M91, 1843-14)

beḍüp / bẹ̣üp(M133, 2451-7)

beḍür / bẹ̣ür(M86, 17571; 91, 1841-12)

beḍ̈se / bẹdüse(M114, 2168-1; 98, 1928-1)

bedüt / bẹdüt(M81, 169117)

beḍüt(Mt)i / bẹdütti(M96, 1905-6)

beḍütse / bẹ̣ütse(M121, 2279-8)

beg / bẹg(M110, 212117;111, 2136-17;113, 2166-16;94, 1882-8; 1602-13;100, 1956-1;100, 1966-12;100, 197117;101, 1972-1;101, 1977-9;101, 1985-18;102, 1987-2;102, 1989-4;103, 2005-5;103, 2014-15;103, 2016-17;104, 2017-1;104, 2024-10;104, 202713;105, 2043-13;106, 2056-11;106, 206015;107, 2070-11;108,
2080-4;108, 2081-5;108, 2082-6;108， 2083-7;108, 2091-16;110, 2110$13 ; 110, \quad 2113-8 ; 110$, 2117-13;111, 2122-1;111, 2125-4;111, 2128-7;111, 2130-10;111, 213516;112, 2138-2;112, 2139-3;112, 2143-7;112, 2144-8;112, 2145-9;113, 2165-13;114, 2168-1;115, 2182-1;120, 2259-1;120, 2261-3;126, 2354-12;130, 2413-12;130, 2416$15 ; 132, \quad 2442-12 ; 136$, 2504-18;137, 2513-9;76, 1609-3;79, 1658-11;86, 1757-1;86, 1759-13;86, 1760-4;87, 1779-8;94, 1879-5;94, 1884-10;97, 1924-13;98, 1934-8;98, 1936-11;98, 1936-11;99, 1950-11;99, 1950-11;99, 1953-14)

begde / bẹgde(M101, 1984-17)

begdin / bẹgdin(M111, 2135-16)

begi / bẹgi(M , 15944;100, 1962-8;100, 19639;100, 1968-14;104, 2029-15;109, 210312;109, 2106-16;109, 2107-17;110, 2114-9;114, 2172-5;118, 2239-12;119, 2246-3;131， 2422-5;76, 1610-4;86, 1758-2;88, 1789-2;89, 1809-7;97, 1919-7)

begim / begim(M , 160213)

begin / bẹgin(M120, 2260-2; 94, 1882-8) begin / bẹin(M94, 18806)

beginde / biginde(M115, 2193-13)

begine / bẹine(M137, 2506-2; 139, 2546-15; 94, 1883-9) begke / bẹgke(M102, 1988-3;103, 2013-14;106, 2049-4;106, 2060-17;107, 2071-12;108, 2079-2;108, 2079-3;111, 2124-3;115, 2182-1;119, 2256-15;120, 2270-13;131, 2420-2;135, 2490-16)

begler / begler(M102, 1986-1;103, 2011-11;103, 2014-15;104, 2020-5;104, 2021-6;104, 2026-12;104, 2027-13;105, 2036-5;105, 2037-6;106, 2050-5;107, 2063-1;107, 2076-17;109, 2107-17;110,

211013;110, 2111-4;110, 2113-8;110, 2116-12;110, 2118-14;111, 213010;112, 2139-3;115, 2183-2;116, 2210-15;116, 2211-16;119, 2245-2;119, 2247-4;119, 2258-17;120, 2266-9;130, 2412-11;130, 2416-15;133, 2449-5;136, 2493-5;137, 2514-10;76, 1609-3;76, 1611-5;77, 1630-11;77, 1631-10;77, 1632-12;82, 1694-3;85, 1755-16;89, 1806-14;89, 1807-5;96, 1905-6;96, 1906-7;98, 1931-5;98, 1935-10;98, 1935-10;99, 1952-13)

begleri / bẹgleri(M108, 2092-17; 94, 1885-11)

beglerke

bẹglerke(M114, 2181-16) beglik / bẹglik(M100, 1960-6;104, 2021-6;104, 2026-12;104, 203016;105, 2036-5;109, 2104-14;111, 2127-6;98, 1931-5;98, 1933-7;98, 1935-10)

beglik / bẹglik(M100, 1970-16;102, 1988-3;104, 2018-2;104, 2018-2;106, 2059-14;109, 2093-2;109, 2094-3;112, 2137-1;113, 
$2155-4 ; 115, \quad 2183-2 ; 98$, 1935-10; 104, 2027-13) begliki / bẹgliki(M100, 1969-15)

bẹglikin / bẹglikịn(M98, 1932-6)

beglikke / bẹglikke (M97, 28. başlık; 99, 1949-10) bek / bẹk(M82, 1698-7) bekledi / bẹkledi(M103, 2016-17)

beklenür bẹklenür(M106, 2050-6) bekletip / bẹkletip(M139, 2535-3)

bekliki / bẹkliki(M111, 2132-12)

bekütügli

bẹkütügli(M115, 2183-2)

belgü / bẹlgü(M102, 1997-14; 78, 1650-16)

belgülüg

bẹlgülüg(M108, 20815;110, 2116-12;121, 2286-15;131, 243014;133, 2458-16;136, 2501-14;138, 2523-4;82, 1694-3;90, 1829-13;91, 1837-7;95, 1901-17;95, 1901-17;96, 1902-1)

belgülük / bẹlgülük(M91, 1841-12; 93, 1873-16)

belgüsi / bẹlgüsi(M90, 1828-12; 93, 1864-6)

berk / berk(M126, 23474; 136, 2504-18; 87, 1784-14; 89, 1810-8)

berü / bẹrü(M98, 1941-

17)

çerig / çẹrig(M120, 2272-

15 ; 124, 2328-14; 125, 2333-3; 127, 2371-16; 128, 2380-9; 128, 238110)

çerig-de / çẹrig-de(M127, 2370-15)

çerigde / çẹrigde(M84, 1736-12)

çerigin / çẹriginn(M120, 2268-11) çerigke / çẹrigke(M128, 2375-3)

çiçcek / çịçẹk(M89, 18086)

çiçekler / çịçẹkler(M89, 1810-8)

ẹcẹlsiz / ecẹlsiz(M122, 2288-3)

ẹmanẹt / emanẹt(M83, 1770-14; 84, 1729-5)

emgek / emgẹk(M93, 1874-17)

erse / irse(M107, 2066-6; 126, 2357-17)

hạşmẹt / hạşmet(M123, 2303-2)

himmet / hịmmẹt(M111, 2124-3; 111, 2125-4)

hụccet /huccẹt(M111, 2129-9)

kalır / kẹlir(M136, 2502-

16)

keçer / kẹçer(M , 1583-7;

101, 1977-9; 84, 1735-11)

keçig / kẹçig(M88, 17937)

keçip / kęçip(M135, 2485-10)

keçse / kẹçse(M115, 2186-5)

keçti / kẹçti(M82, 1695-4)

keçürdi / kẹçürdi(M94,

1888-15)

keçürgen

kẹçürgen(M114, 2170-3)

keçürgey

kẹçürgey(M137, 2512-8)

keçürmiş

kẹçürmiş(M108, 2088-12; 120, 2271-14; 127, 236711; 88, 1798-13; 99, 1955-16)

keçürse / kẹçürse(M109, 2094-3; 111, 2122-1)

keçürsün / kẹçürsün(M97, 1920-8)

ked / kẹd (M102, 19894;102, 1992-7;102, 199410;103, 2014-15;114, 2169-2;117, 2217-6;118,
2234-7;124, 2328-14;126, 2345-2;126, 2345-2;126, 2347-4;126, 2350-8;127, 2268-13;128, 2373-1;129, 2400-13;132, 2436-5;132, 2440-10;133, 2448-4;134, 2469-11;134, 247012;134, 2473-15;134, 2474-16;135, 2480-5;136, 2492-5;138, 2529-12;138, 2532-16;77, 1626-6;78, 1639-3;82, 1707-17;96, 1904-4;96, 1911-14;97, 1923-12)

keḍ ök / kẹ̣ük(M100, 1958-4)

keḍgülük

kẹdgülük(M132, 2439-9)

keḍgüsi / kẹdgüsi(M101, 1982-14)

keḍig / kẹdig(M129, 2400-13)

keḍim / kẹdim(M121, 2280-9)

kedürse / kẹdürse(M121, 2280-9)

keldi / kẹldi(M136, 2491$1 ; 83,1713-6$ )

kelin / kẹlin(M128, 23809)

kelip / kẹlip(M82, 170212 ; 83, 1709-3; 86, 1769-

14)

kelir / kẹlir (M77, 16232;100, 1966-12;132, 2439-9;132, 2444-15;134, 2474-16;136, 2502-15;82, 1703-13;83, 1714-7;98, 1931-5)

keliş / kẹliş(M136, 24957)

kelmeginçe

kẹlmeginçe(M121， 228615)

kelü / kẹlü(M83, 1715-8)

kelür / kẹlir(M91, 184112)

kelür / kẹür(M109, 2101-

10) 
kemişmegil

kẹmişmegil(M96, 1908-9)

kemişse / kẹmişse(M121, 2285-14; 128, 2375-3; 128, 2386-16)

kenç / kẹnç(M106, 2056$11 ; 106,2056-11)$

kendü / kẹndü(M129, 2400-13)

kerek / kẹrek(M100, $1957-2 ; 100, \quad 1961-7 ; 100$, 1963-9;100, 1963-9;100, 1971-17;101, $\quad 1981-$ $13 ; 101, \quad 1985-18 ; 102$, 1989-4;102, 2000-17;103, 2005-5;103, 2010-10;103, 2014-15;105, 2038-7;105, 2043-13;105, 204414;106, 2049-4;106, 2057-12;106, 205712;106, 2058-13;107, 2071-12;107, 207213;108, 2083-7;108, 2087-11;108, 209015;108, 2091-16;111, 2122-1;111, 2124-3;111, 2124-3;111, 2127-6;111, 2127-6;111, 2131-11;113, 2164-12;114, 2177$11 ; 115, \quad 2182-1 ; 115$, 2184-3;115, 2186-5;115, 2187-6;115, 2187-7;115, 2188-8;115, 2188-8;115, 2190-10;116, 2199-3;116, 2200-14;116, 2208$13 ; 117, \quad 2218-7 ; 118$, 2234-7;118, 2234-7;120, 2266-9;120, 2270-13;120, 2271-14;121, 2282$11 ; 121, \quad 2282-11 ; 121$, 2282-11;121, 2282$11 ; 121, \quad 2285-14 ; 121$, 2285-14;122, 2289-4;122, 2298-13;122, 229914;122, 2299-14;122, 2300-15;123, 2303-2;123, 2303-2;123, 2309-11;123, 2310-2;123, 2310-2;123, 2313-15;124, 2317-2;124, 2317-2;124, 2323-9;124,
2324-10;124, 2325$11 ; 124, \quad 2326-12 ; 124$, 2327-13;124, 232814;124, 2328-14;125, 2332-2;125, 2332-2;125, 2337-8;126, 2351-9;126, 2351-9;126, 2356-14;129, 2399-12;130, 2410-8;130, 2415-4;130, 2415-4;131, 2420-2;132, 2436-5;132, 2436-5;132, 2437-6;132, 2441-11;132, 244111;133, 2449-5;133, 2458-15;134, 2461-2;134, 2469-11;134, 2469$11 ; 134, \quad 2473-15 ; 134$, 2474-16;135, 2480-5;135, 2483-7;135, 2485-10;135, 2487-13;135, 2487$13 ; 135, \quad 2488-14 ; 138$, 2524-5;138, 2529-12;138, 2529-12;139, 2534-2;139, 2534-2;85, 1742-2;85, 1742-2;89, 1811-9;96, 1910-12;96, 1910-12;97, 1924-13;99, 1949-10;99, 1951-12;99, 1951-12;99, 1951-12;99, 1951-12;99, 1954-15; 114, 2168-1; 116, 2211-16; 118, 222912 ; 121，2273-1; 134, 2464-5; 138, 2527-9)

kereki / kẹreki(M114, 2175-5)

kereki / kẹreklik(M76, 1619-13)

kerekin / kẹrekin (M114, 15. başlık; 120, 30. başlık; 138, 10. başlık) kerekini / kẹrekini (M97, 28. başlik)

kereksiz / kẹreksiz(M108, 2079-2; 110, 2115-10; 121, 2283-12; 125, 23322)

kerişi / kẹrişi(M112, 2150-15)

kesgil / kẹsgịl(M127, 2363-5) kesildi / kẹsildi(M137, 2516-12)

kesilse / kẹsilse(M139, 2540-9)

lẹvh-u / levh-u(M117, 2227-17)

meliklerke

mẹlịklerke(M138, 25223) men / mẹn(M , 15933;113, 2164-12;77, 1627$7 ; 77, \quad 1628-8 ; 95, \quad 1895-$ $9 ; 98, \quad 1939-15 ; 98,1939-$ 15)

menin / mẹnin(M114, 2174-7)

men / mẹy(M106, 205410)

mẹnelig / menelig(M88, 1789-2)

meniz / mẹniz(M128, 2384-12)

meyzer / mẹyzer(M130, 2407-4; 135, 2486-11; 142, 2578-2)

meyzetü / mẹyzetü(M101, 1974-4;107, 2065-4;136, 2491-1;88, 1798-13;89, 1812-10;90, 1826-10;95, 1900-15)

meyzetür

mẹyzetü(M134, 2466-7)

neçe / nẹce(M102, 19939;102, 1998-15;102, 1998-15;102, 1998$15 ; 109, \quad 2101-10 ; 109$, 2101-10;109, 2102$11 ; 109, \quad 2102-11 ; 116$, 2198-2;136, 2501-14;84, 1738-15;89, 1814-3;90, 1827-11;90, 1831-16;92, 1856-13;92, 1856-13) negü / nigü(M78, 1638-2) nelük / nẹlük(M106, 2056-11; 80, 1674-13; 122, 2287-2)

ney / nẹp(M103, 20099;103, 2015-16;104, 2023-8;106, 2054-10;106, 2057-12;106, 2058- 
13;106, 2060-15;107, 2069-10;107, 2071$12 ; 111, \quad 2132-12 ; 119$, 2252-9;127, 2365-7;129, 2398-11;130, 2405-2;130, 2408-6;130, 2409-7;134, 2467-9;135, 2485-10;135, $2487-13 ; 137, \quad 2507-3 ; 80$, $1667-5 ; 80, \quad 1669-7 ; 80$, $1676-15 ; 86,1769-14)$

ney-de / nẹy-de(M107, 2063-1)

neni / nẹni(M109, 20976)

nenin / nẹpin(M130, 2411-10)

nẹke / nệke(M103, 2004-4;119, 2255-14;130, 2412-11;138, 2523-4;78, 1650-16;78, 1658-17;95, 1897-12)

neyni / nẹpni(M119, 2254-13)

neynin / nẹpin(M127, 2369-14)

nerek / nẹrek(M96, 19067)

neteg / nẹtẹg(M110, 2111-4; 89, 1815-15)

neteg / nẹteg(M131, 2431-15)

sẹbẹb / sebẹb(M89, 1804-

2)

seçer / sẹçer(M117, 2220-

9)

seçildi / sẹçildi(M91, 1843-14)

sekirtip / sẹkirtip(M128, 2381-10)

semritür/ sẹmritür(M96, 1912-15)

sen / sẹn(M104, 20205;104, 2022-7;110, 2121$17 ; 113, \quad 2160-9 ; 119$, 2252-10;120, 2268$11 ; 123, \quad 2307-9 ; 127$, 2362-4;127, 2365-7;130, 2411-10;96, 1910-12;97, 1917-4; 98, 1939-15) senin / sẹnin (M113, 2162-12; 127, 2359-1) senindin / sẹnindin (M93, )

senindin / sẹnindịn(M138, 2526-8)

seninsiz / sẹniøsiz(M92, 1859-16; 93, 1860-2)

sẹrim-lig / serim$\operatorname{lig}(\mathrm{M} 135,2480-5)$

serin / sẹrin(M106, 206116 ; 128, 2386-16)

seringen / siringen(M128, 2379-7)

serịm-lüg / sirimlüg(M93, 1867-9)

sevmezin

sẹvmezin(M95, 1898-13)

sev́er / sev́er(M79, 166114 ; 95, 1895-9; 95, 189813 ; 96, 1902-1)

sev́eri / sẹveri(M112, 2150-15)

sev́erin / sẹverin(M95, 1896-11)

sev́inç / sẹvinç(M87, 1774-2)

sev́inç / sev́ịnç(M111,

2135-16)

sev́inçi / sẹvinçi(M101, 1984-17; 128, 2380-9)

sev́inçi / sẹvinçi(M112, 2148-13)

sẹvinçi / sẹvinçi(M76, 1609-3)

sev́inçin / sẹvinçin(M123, 2304-3)

sev́inçin / sẹvinçinin(M101, 1977-9; 137, 2512-8)

sev́inçin / sẹvininçīin(M112, 2145-10)

sev́indi / sẹvindi(M93, 1872-15)

sev́inlig / sẹvinçlig(M112, 2145-9)

sev́itmiş / sẹvitmiş(M95, 1893-5)

sev́itür / sẹvitür(M118, 2229-12; 118, 2230-3; 133, 2459-17) sev́megüçi

sẹv́megüçi(M112， 2150-

15)

sev́mez / sẹv́mez(M87,

1773-1)

sev́mezin

sẹv́mezin(M96, 1902-1)

sev́seler / sẹv́seler(M122, 2299-14)

sev́üg / sẹvüü(M118, 2232-5; 121, 2281-10; 130, 2404-1; 95, 1896-11) seviügsüz

sẹvügsüz(M118, 2232-5)

sev́ülse / sẹvülse(M107, 2071-12)

sịyaset / sịyasẹt(M111, 2130-10)

teg / tẹg(M , 1583-7;110, 2121-17;114, 2177$11 ; 117, \quad 2213-1 ; 117$, 2216-15;122, 2288-3;122, 2288-3;123, 2311-13;123, 2311-13;123, 231113;123, 2312-14;123, 2312-14;123, 231315;123, 2314-6;127, 2369-14;128, 2377-5;128, 2377-5;130, 2413-12;131, 2424-7;138, 10. başlık;138, 2527-9;76, 1617-11;82, 1704-14;94, 1882-8;97, 1924-13; 106, 2060-15; 95, 1895-9; 120, 2266-9)

teg / tig (M114, 15. başl1k)

tegdi / tẹgdi(M133, 24484 ; 86, 1772-17; 87, 178212)

tegdim / tẹgdim(M89, 1803-1)

teger / tẹger(M130, 241413)

tegimlig / tẹgimlig(M133, 2446-2)

tegir / tẹgir(M90, 18204;94, ; 116, 2209-14; 118, 2239-12; 88, 1797-12; 93, 1874-17) 
tegir / tẹgirir(M88, 180116)

tegiş / tẹgiş(M128, 2377$5 ; 128,2377-5)$

tegişgü / tẹgişgü(M128, 2375-3; 128, 2376-4)

tegme / tẹgme(M , 159015;106, 2045-1;112, 2151-6;112, 2152-17;113, 2166-16;137, 2506-1;139, 2533-1;139, 2546-15;86, 1770-15)

tegmedi / tẹgmedi (M93, )

tegmese / tẹgmese(M114, 2180-14; 121, 2273-1)

tegmez / tẹgmez(M104, 2029-15; 118, 2233-6)

tegrür / tẹgrür(M120, 2260-2; 126, 2348-6; 131, 2428-12; 94, 1880-6)

tegse / tẹgse(M104, 2029-

15;114, 2180-14;116, 2208-13;92, 1853-9;92, 1855-12;92, 1856-13)

tegümedi

tẹgümedi(M88, 1794-8)

tegür / tẹgür(M123, 2304-

3; 85, 1742-2; 90, 1823-7;

93, 1867-9)

tegürgü / tẹgürgü(M90, 1822-6)

tegürmez

tẹgürmez(M103， 2006-6; 119, 2246-3)

tegürse / tẹgürse(M139, 2547-16)

telim / tẹlim(M , 1592-

2;105, 2035-4;121, 2280-

$9 ; 125, \quad 2340-12 ; 127$, 2359-1;137, 2516-12;77, 1635-15;82, 1698-7;87, 1773-1;97, 1915-2)

telimrek / tẹlimrek(M112, 2150-15; 112, 2148-13)

ten / tẹn(M124, 2317-2; 135 , 2481-6; 135, 248814)

tệ / tig(M78, 1650-16) tẹy / tigg(M78, 1650-16; 78, 1658-17)

teneşçi / tịneşçi(M119, 2256-15)

teninçe / tẹninçe(M81, 1690-16)

teninçe / tẹninçęe(M108, 2090-15)

teniş / tẹniş(M136, 24957)

teniz / tẹniz(M115, 21854)

tenizke / tẹnizke(M84, 1733-9)

teyler / tẹpler(M132, 2440-10; 132, 2440-10)

tẹlese / tệlese(M126, 2352-10)

teylig / tệlig(M91, 183910)

tensiz / tẹnsiz(M103, 2008-8; 137, 2511-7)

teysiz / tẹnsizz(M109, 2107-17; 103, 2006-6; 109, 2102-11)

tejsizin / tẹnsizig(M79, 1662-15)

teysizin / tệsizin(M109, 2107-17)

tepner / tẹpner(M112, 2144-8)

tepregil / tẹpregil(M128, 2387-17)

tepremedi / tẹpremedi(M , 1606-17)

tepremez

tẹpremez(M112, 2144-8)

teprenürke

tẹprenürke(M92, 1852-8)

teprese / tẹprese(M126,

2346-3; 128, 2387-17)

tepretmese

tẹpretmese(M139, 2536-

5)

ter /tẹr(M76, 1608-2)

terk / tẹrk(M142, 2580-5)

terkin / tẹrkin(M129, 2398-11)

ters / tẹrs(M112, 2146-11; 98, 1930-4; 92, 1856-13) tersi / tẹrsi(M96, 1907-8)

tezgin / tẹzginn(M85,

1742-2)

yenç / yẹnç(M104, 2022-

7)

yençmek

yẹnçmek(M104, 2025-11)

yençse / yẹnçse(M126,

2352-10)

yẹnçse / yençse(M97,

1926-15)

yençti / yẹnçti(M103,

2016-17)

yenip / yẹnip(M79, 1654-

4)

yeter / yẹter(M92, 1858-

15)

yetgü / yẹtgü(M128, 2388-18)

yetilmiş / yẹtilmiş(M86, 1758-2)

yetilmiş / yẹtịlmiş(M83, 1724-18)

yetilse / yẹtilse(M78, 1647-12; 81, 1678-1)

yetlü / yẹtlü(M92, 18539)

yetlür / yẹtlür(M81, 16837; 97, 1919-7)

yetmez / yẹtmez(M103, 2001-1)

yetmiş / yẹtmiş̧(M85, 1746-7)

yetrü / yẹtrü(M130, 2407$4 ; 135,2484-9)$

yetrüp / yẹtrüp(M , 15944)

yetrür / yẹtrür(M104, 2029-15)

yetse / yẹtse(M109, 20932;109, 2094-3)

yetür / yẹtür(M106, 20539) yetürgen yẹtürgen(M124, 2316-1) yezek / yẹzek(M125, 2342-16;125, 2343-17) 


\section{1. 3. /1/ Ünlüsü}

172 örnekte /1/ ünlüsünün yazımıyla ilgili farklılık tespit edilmiştir.

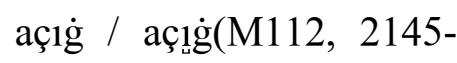
10) adırṭ̣ / adirtı̣(M91, 1833-2)

aġır / ag் $\dot{g}_{\mathrm{u}} \mathrm{r}(\mathrm{M} 84,1725-1)$

aġırladi / ağ 1717-10)

aġırlık / ag்ırlıḳ(M83, 1718-11)

andin / andin(M136, 2502-16)

anın / anın(M101, 1981$13 ; 78,1646-11)$

anın / anın(M101, 197911 ; 82, 1698-7; 82, 170414)

anıyda / anı̋jda(M112, 2138-2)

anındın / anındın(M113, 2166-16)

arı̇glı̣ / arı̣glı̣(M101, 1985-18)

arig்s1z / arịssiz(M102, 1987-2; 115, 2194-14)

arig்sızn1

arı̣̆sızn1(M110, 2108-1)

atın / atın(M120, 2259-1)

ayayın / ayay!̣(M97, 1920-8)

ayık-lı $\dot{\mathrm{g}} /$ ay!̣ $\mathrm{k}-1 \mathrm{~g} \dot{\mathrm{g}}(\mathrm{M} 121$, 2286-15)

ay1t(Mt)1 / ay!̣t(Mt)1 (M98, 1930-4)

ayıtgu / aỵ̣tgu(M114, 2176-10; 91, 1832-1)

ayıtg் / ayıtgì(M97, 1921-10)

ayıtmak / ayı̣tmak(M96, 1907-8)

ayıtmazda

ay!̣tmazda(M137, 2520-

17)

ayıtmış / ayıtmı̣ş(M96, 1910-12) ayıtmış / ayı̣tmış(M138, 2525-6)

av́1nç1 / av́ṇç̧1(M92,

1849-4)

av́ınçın / av́ịçın(M94,

1886-12)

av́ınsa / av́ı̉nsa(M109,

2093-1)

baġırḳa / bạgirḳa(M99,

1947-8)

baġırsaḳ / bạg̣̣̣rsak(M113, 2160-9; 94, 1881-7; 99, 1942-1; 99, 1943-3)

baġırsak / bạgigirsak(M111, 2123-2; 99, 1945-5; 99, 1946-7)

baġırsaḳ /bag̣̣ırsaḳ(M114, 2169-2)

baġırsakḳa

bạgıırsakka(M84, 1728-4)

bağırsakkạa

bạğı̧rsakka(M99, 1943-2)

bag̈ırsaḳlıḳı

bạğgırsaḳlıḳ1(M107, 2073-

14)

baġırsaḳlıḳın

bạğırsaḳlı̣kın(M131,

2432-16)

baġırsaḳlıkıın

bạg gुrsaḳlıkıın(M99, 1944-

4)

baġırsak-1ıḳı / bạgı̀rsaḳl1kın(M94, 1878-9)

bạg̣̣ırsaḳ / bạgirırsaḳ(M138, 2529-12)

baylı̣ / baylık(M85, 1747-8)

bạytı $\dot{g}$ / baytı̇g(M105, 2046-15)

bolayın / bolay!̣n(M77, 1634-14)

bolmışın / bolmı̣şın(M97, 1920-8)

bulayın / bulay!̣n(M85,

1745-6)

canın / canın(M131,

2432-16)

çav́1ksa / çav́ı $1 \mathrm{usa(M80,}$ 1671-9) çı̇̉ayḳa / çı̇gayḳa(M87, 1786-16)

çı̇̉aylıḳ / çı̇gaylıḳ(M109, 2096-5)

çıkssa / çı̣sa(M133, 2459-

17)

çıkssa / çıkssa(M139, 2535-

3)

çın / çı̂n(M103, 2010-10;

130, 2407-4)

çırg̉uy / çırg̉uy(M80, 1673-11)

hạḳıı/ hạkı̣ın(M77, 163414)

1ng்a / ına(M107, 2064-2)

kalın / kalın(M114, 2178-

12)

ḳalın / ḳalın(M77, 16221)

kạrımas / kạrımas(M120, 2263-5)

ḳarımaz / kạrı̣maz(M78, 1639-3)

ḳarışsa/ ̣arı̣ssa(M128, 2384-13)
9)

ḳatlıp / ḳatlı̣p(M81, 1682-

6)

ḳayır-ça / ḳaỵ̣r-ça(M83, 1723-17)

ḳ1layın / ḳılayın(M77, 1634-14)

ḳ1dı / kıldd1(M , 1605-16)

k1ld1 / kıld1(M120, 2259-

1; 76, 1611-5; 83, 1716-9; 86, 1760-4; 94, 1886-12)

kılg̀u / ḳ1 ligu(M107, 20688)

ḳılġuçı / ḳılġuçı(M98, 1938-14)

ḳılıç / ḳılı̧ç(M112, 21448 ; 128, 2377-5; 128, 2377-5)

ḳ1lıç / kụlıç(M126, 235412)

ḳ1lıç / kụlı̣ç(M131, 2426-

9)

ḳ1lıç / kılıç(M107, 20699;112, 2138-2;112, 2139- 
$3 ; 112,2141-5 ; 112,2143-$ $7 ; 112,2143-7 ; 112,2144-$ $8 ; 112,2145-9 ; 113,2155-$ $4 ; 130, \quad 2418-17 ; 131$, 2425-8;84, 1736-12; 112, 2140-4)

ḳ1lı̧ın / ḳ̣lı̣çın(M112, 2140-4)

ḳ1lıçsız / ḳ̂ulı̧̧sız(M112, 2139-3)

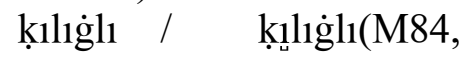
1729-5)

ḳ1lı̈l1 / ḳ!lı̈̆l1(M124, 2321-7)

ḳ1lı̣ / ḳ1lịk(M90, 1824-8)

kılık / kıllke(M101, 1978$10 ; 103,2012-13$ )

kılık / kılık(M107, 207718; 110, 2110-13)

kı1lḳ1 / kı1lıkı(M117, 221514)

kı1ın / ḳ1ın(M134, 246810)

ḳ1lınç / ḳ̣lınç(M101, 1981-13; 101, 1983-15; 107, 2064-2; 107, 2066-6; 113, 2161-11; 79, 165912; 79, 1664-17; 90, 1824-8)

ḳ1lnç / k্̉ılınç(M101, 1982-14; 101, 1984-17; 106, 2060-17; 107, 20666; 116, 2212-17; 135, 2476-11; 86, 1771-16)

ḳ1lınç1 / ḳ1ınnçı(M101, 1980-12; 92, 1850-6)

ḳ1lınçı / ḳ̣lınçı(M118, 2235-8; 134, 2461-2; 91, 1837-7)

ḳ1lınçı / ḳ1lınçı(M138, 2531-15; 92, 1849-4)

ḳ1lınçı / ḳ1lınçı(M100, 1965-11; 102, 1997-14; 103, 2005-5; 107, 2067-7; $116,2197-1$; 132, 244010; 93, 1868-10; 93, 1870-13)

ḳ1lınç1 / ḳılınçı(M101, 1977-9; 107, 2072-13; 108, 2089-14; 109, 2098-
7; 116, 2208-13; 116, 2209-14; 117, 2215-14; $135,2488-14 ; 80,1670-8)$ ḳılınçın / ḳılınçın(M115, 2193-13; 132, 2444-15)

ḳlınçın / ḳlıınçın(M121, 2279-7)

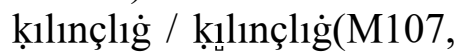
2064-3)

ḳılınçlıg / ḳ̂̉lınç-lig்(M87, 1778-7)

ḳılıp / ḳ̣lıp(M86, 1769-

14)

kı1k / kı̣lk(M110, 211013; 98, 1934-9)

k1lk1 / k1lk1(M134, 24668; 138, 2531-15; 92, 1852-8)

ḳ1lḳ1 / ḳılḳ1(M100, 197016;101, 1977-9;101, 1980-12;101, 198518;102, 1987-2;102, 1997-14;102, 200017;103, 2006-6;105, 2038-7;106, 2049-4;108, 2078-1;109, 2098-7;111, 2128-7;114, 2170-3;116, 2209-14;116, 221217;119, 2246-3;119, 2257-16;123, 2306-6;132, 2437-6;82, 1695-4)

ḳ1lḳın / ḳ1ḳın(M99, 1942-

1)

ḳılḳın / ḳ̣lḳıın(M85, 175516)

ḳ1mad1 / ḳlmadi(M83, 1723-17)

ḳlmag̉ / ḳllmag̉u(M109, 2101-10)

ḳ1mag̉usın/

ḳllmag̉usın(M107, 20677)

kı1maz / ḳ!lmaz(M86, 1760-4)

ḳılmış / ḳılmı̣ş(M102, 1998-15; 102, 1998-15)

ḳılmışı / ḳılmı̣şı(M85, 1753-14)

ḳılmışın / ḳılmı̣şın(M118, 2228-1) ḳ1lmışın / ḳ̂lmışın(M117, 2223-12)

kilsa / kulsa(M109, 210717 ; 120, 2266-9; 132, 2433-1; 100, 1971-17)

kılur / ḳlur(M132, 244314)

ḳ1ur / kılur(M107, 20677; 115, 2192-12; 134, 2462-3)

kı1lı̣ı / ḳ̂llı̣ı1(M93, 18657) ḳınḳa / ḳıḳa(M112, 2144-8)

ḳıp ḳızıl / ḳ̣p ḳ̣zıl(M128, 2385-14)

kı1r ve / kııg்11(M127, 2371-16; 127, 2372-17)

kı1run / kı̣run(M84, 173714)

ḳısga / ḳısga(M108, 208914)

kııyı̣ / ḳıyıḳ(M83, 1723 17)

kııı̣ksız / kıııı̣sız(M ， 1605-16)

kı1z / kı̣(M121, 2278-6; 128, 2380-9)

kı1z1l / ḳız1l(M123, 231214 ; 129, 2398-11; 135, 2483-7; 128, 2385-15)

ḳ1z1l / kı̣z1(M128, 238413)

ḳ1sa / ḳ1sa(M131, 243216)

kı̣ı!̣lmadı

ḳ1yıllmadı(M79, 1562-2)

otın / otın(M110, 2109-2)

saḳınç / saḳın (M , 15848)

saḳınç / saḳınç(M , 158712; 103, 2013-14)

saḳınç / sạḳınç(M101, 1984-17)

saḳ1-nuk / sạk1nuk(M102, 1986-1; 109, 2100-9)

saḳ1ş / saḳış̧(M117, 22209; 117, 2221-10; 117, 2219-8) 
saḳlıḳ / saḳlıḳ(M103, 2015-16; 104, 2020-5)

sạḳıuk /sạkııuḳ(M115, 2192-12)

sançmış / sạnçmı̣ş(M125, 2335-6)

taḳış / tạkı̧̣s(M127, 2365-

7)

tat1 $\dot{\mathrm{g}} /$ tat1 $\dot{\mathrm{g}}(\mathrm{M} 112,2152-$

17 ; 95, 1890-1; 95, 1892-

4; 95, 1893-6; 97, 1915-2)

tatıgin / tatı̇gdın(M95,

1891-2)

tındurur / tı̣ndurur (M94,

)

tını่̇lı / tınıํำ (M85, )

tıryaḳın / tırıakıı(M128, 2377-5; 128, 2377-5)

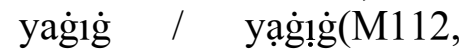
2141-5)

yag்ı $\dot{g}$ / yạg $\dot{g} \dot{g}(\mathrm{M} 104$, 2028-14; 125, 2343-17)

yaġınçı / yạğ̣̣̂ı̧ı(M127, 2371-16)

yag்ıs1 / yạg̣!sı(M99,

1954-15)

yaḳın / yạkı̣n(M119, 2247-4;125, 2341-14;76, 1612-6)

yaḳmaz / yạkmaz(M115, 2192-12;119, 2250-7;133, 2445-1)

yarık / yorı̣k(M107, 2077-

18)

yarlıġını / yarlı̀gnı(M , 1589-14)

y1ġaç / y!̣̇aç(M133, 2455-12)

yı̈̇lu / y!̣glu(M106, 2051-

7)

yı̇gsa / y!̣̇ga(M126, 2347-

5)

y1l / y1̣1(M1 17, 2225-15)

y1l / y11(M131, 2427-11)

yıldız / y!̣ldız(M111,

2132-12)

yıldızı $\dot{g}$ / yı̣dızig்(M109, 2103-13) y1lın / ỵ̣lın(M132, 24354 ; 142, 2579-4;85, 175516)

yılḳ1 / yı̣lḳı (M91, 1845-

17)

yılḳ1 / y1lk1(M105, 2041-

11)

yılḳıdın / yı̣lḳıdın(M91,

1843-14)

yıpar / y!̣par(M98, 1937-

13)

yıraḳ / ỵ̣rak (M139, 2534-2; 102, 1990-5; 107, 2063-1; 116, 220510;116, 2205-10;127, 2268-13;129, 2390-2) yırak / yı̣raḳ(M106, 206015; 107, 2074-15;108, 2078-1;123, 2313-15;126, 2347-5; 92, 1855-12)

yiratur / yiratur(M122, 2295-10)

yorigil1 / yorıglı(M76, 1618-12)

yorıḳı / yorı̣ıı(M126, 2346-3)

yorısa / yorı̣sa(M110, 2113-8)

yunçı $\dot{\mathrm{g}}$ / yunçı่̇(M108, 2089-14)

ỵ̣ramış / yıramış(M137, 2506-2)

\section{1. 4. /i/ Ünlüsü}

482 örnekte /i/ ünlüsünün yazımıyla ilgili farklılık tespit edilmiştir.

'ạịb / 'ạyib(M78, 16449)

açıg / açı่̇(M112, 2145-

10)

begin / bẹgin(M94, 18806)

beglik / bẹglik(M100, 1970-16;102, 1988-3;104, 2018-2;104, 2018-2;106, 2059-14;109, 2093-2;109, 2094-3;112, 2137-1;113,
2155-4;115, 2183-2;98, 1935-10; 104, 2027-13)

bẹglikin / bẹglikinin(M98, 1932-6)

bildi / bildi(M98, 1935-

10)

bildin / bildin(M99, 1942-

1)

bile / bile(M104, 20216;106, 2051-7;107, 2069$10 ; 124,2322-8$;90, 18204;91, 1843-13)

bileyin / bileyịn(M119, 2251-8)

bileyin / bileyin(M95, 1898-13)

bilge / bilge(M117, 22187; 90, 1820-4)

bilgey / bịlgey(M95, 1898-13)

bilgi / bịlgi(M113, 216717; 118, 2243-17)

bilgi / bilgi(M90, 1820-4; 90, 1827-11; 96, 1907-8)

bilgilig / bịliglig(M134, 2466-8)

bilgisizke

bịligsizke(M102, $1997-$

14)

bilgü / billgü(M104, 2027-

13; 95, 1897-12)

bilgüçi / billgüçi(M117, 2214-14)

bilgüçiler

bịlgüçiler(M89, 1815-15)

bịlig / bilig(M81, 1680-4)

bilig / bịlig(M113, 216412;118, 2238-11;133, 2447-3;135, 2483-7;135, 2488-14;138, 2524-5;90, 1822-6;90, 1823-7;96, 1906-7)

bilig / billig(M114, 21755; 133, 2450-6; 93, 187215)

bilig / bilig(M134, 24667;89, 1813-12; 91, 184517; 104, 2029-15; 99, 1952-13; 80, 1673-11) 
bilig / bịlig (M98, 1930$4 ; 100,1958-4 ; 100,1967-$ $13 ; 100, \quad 1968-14 ; 100$, 1968-14;102, $\quad 1994-$ $10 ; 118, \quad 2243-17 ; 133$, $2451-7 ; 79, \quad 1658-11 ; 81$, $1680-4 ; 81, \quad 1681-5 ; 81$, $1683-7 ; 89, \quad 1814-3 ; 89$, $1815-15 ; 90, \quad 1824-8 ; 90$, $1825-9 ; 91, \quad 1845-17 ; 92$, 1846-1;92, 1846-1;96, 1905-6;97, 1927-16)bịlig / bịlig(M98, 1940-16;99, 1947-8;99, 1953-14; 99, 1955-16)

bilig / bilig(M100, 197016;109, 2095-4;117, 2218-7;132, 2441-11;81, 1679-3;87, 1784-14;99, 1953-14)

bịlig-de / bịlig-de(M91, 1843-14)

bilig-de / bịlig-de(M91, 1833-2)

biligdin / bịliggdin(M89, 1804-2; 87, 1775-4)

biligin / bịligin(M91, 1841-12)

biligin / biligin(M91, 1843-14)

biligke / bịligke(M90, 1818-2; 90, 1820-4)

biligke / biligke(M90, 1822-6)

biligli / bịligli(M118, 2236-9)

biligli / bịligli(M98, 1938-14; 99, 1954-15)

biligli / billigli(M91, 1840-11)

bịlig-lig / bịlig-lig(M87, 1777-6; 87, 1781-11)

biliglig / bịliglig(M115, 2188-8)

biliglig / bịliglig(M83, $1710-4 ; 84,1727-3 ; 84$, 1740-17)

biliglig / bịliglik(M110, 2117-13) biliglig / bịliglig(M97, 1923-12)

biliglig / bịliglig(M100, 1956-1;100, 1964-10;100, 1971-17;101, 1972-1;104, 2031-17;108, 2090$15 ; 113, \quad 2167-17 ; 133$, 2452-9;133, 2457-14; 99, 1951-12; 99, 1954-15)

biliglig / biliglig(M113, 2167-17; 133, 2448-4; $133,2449-5$; 114, 2168-1) biligligke

bịligligke(M83, 1709-3; 87, 1778-7; 133, 2448-4)

biliglig-ke

biligligke(M87, 1780-10)

biligsiz / bịligsiz(M135, 2486-11; 80, 1669-7; 81, 1680-4; 81, 1681-5; 84, 1739-16)

biligsiz / bịligsiz(M83, 1710-4; 86, 1763-8; 96, 1906-7; 133, 2452-9)

biligsiz / biligsiz(M97, 1923-12)

biligsiz / biligsiz(M84, 1739-16)

bịlig-siz / bịlig-siz(M87, 1781-11)

biligsizke

bịligsizke(M101, 1974-4; 83, 1709-3)

bilig-sizke / bịligsizke(M87, 1780-10)

biligsizni

biligsizni(M109, 2095-4)

bilip / bịlip(M , 1594-4;

102, 1989-4)

bilir / bịlir(M90, 1819-3;

94, 1878-9)

bilir / bilir(M134, 2474-

16)

bilir / bilir(M92, 1857-14;

98, 1931-5)

bilişmes / bịlişmes(M119, 2251-8)

bilmedükin

billmedükin(M96, 190911) bilmiş / bilmịş̧(M76, 1616-10)

bilmiş / bilmişs(M117, 2214-2)

bilmişig / bilmişig (M94, 1889-17)

bilmişin / bilmịşin(M97, 1920-8)

bilse / bilse(M107, 207415; 117, 2218-7; 126, 2345-2; 89, 1814-3)

bilür / bilür(M95, 189611; 98, 1932-6)

bir / bir (M94, 188917;100, 1956-1;101, 1976-8;103, 2015-16;105, 2042-12;114, 217610;121, 2273-1;121, 2277-5;128, 2374-2;129, 2396-8;138， 2526-8;79, 1655-6;85, 1745-6;85, 1748-9;88, 1792-6;91, 1832-1)bir /bir(M106, 2058-13; 131, 2430-14; , 1593-3)

birdi bịrdi(M76, 16071;107, 2070-11;114, 2181-16;120, 2269$12 ; 138, \quad 2528-11 ; 78$, 1642-7;86, 1764-9;86, 1770-15;89, $1805-3 ; 90$, 1817-1;92, 1850-6;96, 1905-6;96, 1911-14;97, 1918-6;98, 1930-4;98, 1940-16;99, 1948-9)

birdin / bịrdin(M87, 1784-14)

birgil / birgil(M88, 17959)

birgü / bịrgü(M129, 239811)

birgü / bịrgü(M130, 24052)

birgüçi / bịrgüçi(M109, 2095-4)

birgüke / birgüke(M116, 2211-16)

biri / bịri(M136, 2504-18) biri / biri(M104, 2024-9; 137, 2508-4; 137, 2508-4; 
$137,2511-7 ; 137,2511-7$; 80, 1668-6)

birig / bịrig(M139, 254615)

birigli / birigli(M87, 1783-13)

birikse / birikse(M131, 2419-1)

birilse / birilse(M89, 1808-6)

birisi / bịisi(M104, 20249; 106, 2061-16; 111, $2133-13 ; 130,2418-17)$ birisi / birisisi(M111, 213313)

birke / birke(M94, 1877-

2)

birle / birle(M100, 19584;100, 1970-16;101, 1978-10;102, 1993-9;105, 2034-3;106, 2049-4;106, 2050-6;112, 2139-3;116, 2197-1;116, 2202-7;116, 2207-12;117, 2215$14 ; 117, \quad 2220-9 ; 117$, 2223-12;118, 2242$16 ; 119, \quad 2255-14 ; 122$, 2289-4;122， 2290-5;128, 2377-5;128, 2377-5;130, 2409-7;131，2428-12;82, 1695-4;82, 1702-12;86, 1769-14;89, 1803-1;89, 1813-12;89, 1816-16;91, 1838-9;91, 1845-17;98, 1940-16;99, 1952-13;99, 1952-13;99, 1953-14; 112, 2141-5)

birme / birme(M128, 2386-16)

birmegü / bịrmegü(M87, 1776-5)

birmese / birmese(M127, 2364-6)

birse / bịrse(M130, $2407-$

4)

birse / birse(M101, 198012;101, 1983-15;106, 2047-2;108, 2085-9;117, 2221-10;138, 253216;139, 2533-1;139,
2546-15;83, 1715-8;90, 1828-12;98, 1933-7)

birsi / birsi(M106, 206116 ; 80, 1668-6)

birsü / bịrsü(M136, 24912; 94, 1877-2)

birür / bịrür(M110, 21092)

birür / birür(M130, 24041; 86, 1762-7; 86, 1766-5 $/ 6 ; 98,1933-7)$

bitig / bịtig(M117, 221414; 117, 2224-13; 117, 2225-15; 117, 2226-16) bitig / bitig(M117, 22187; 117, 2223-12)

bitig / bitig(M135, 24827)

bitigçi / bịtigçi(M136, 2494-6)

bitigli / bịtigli(M118, 2234-7)

bitip / bịtip(M117, 2226-

16; 83, 1722-16)

bitir / bitir(M117, 2223-

12)

bitise / bitise(M117,

2223-12)

çerigin / çẹriginn(M120,

2268-11)

çiçekinde

çiçekinde(M78, 1658-17)

çiçekler / çịçẹkler(M89, 1810-8)

dẹvlẹtin / dẹvlẹtinn(M83,

1715-8)

eḍleyin / eḍleyịn(M77, 1627-7)

elgin / elgin(M107, 20699)

eli / elig(M124, 2320-16)

elig / elig(M112, 2139-3;

77, 1630-11; 97, 1927-16) elig / elig(M87, 1785-15) erinç / erinç(M107, 20643)

erklig / erklig(M89, 18042) erse / irse(M107, 2066-6; 126, 2357-17) eşit (Mt)im

eşit(Mt)îm(M96, 1903-3)

eşit(Mt)i / eşit (Mt)i(M94, 1887-13)

eşitgil / eşitgill(M109, 2095-4; 117, 2214-2; 137, 2513-9; 80, 1673-11; 99, 1955-16)

eşitgil / eşitgil(M110, 2117-13; 127, 2367-10; 83, 1724-18)

eşitgil / eşitgil (M85, başl1k; , 1594-4;100, 1962-8;102, 1992-7;104, 2019-3;104, 2031-17;105, 2040-10;108, 2088$12 ; 109, \quad 2100-9 ; 112$, 2141-5;113, 2153-1;113, 2167-17;115, 219616;116, 2204-9;118, 2243-17;121, 228716;123, 2306-6;124, 2319-5;128, 2379-7;131, 2424-7;135, 2477-2;76, 1608-2;76, 1616-10;76, 1620-15;78, 1638-2;81, 1689-14;94, 1880-6;96, 1913-16;99, 1945-5;106, 2052-8)

eşitmek / eşîtmek(M97, 1914-1)

hiç / hịç(M93, 1863-5; 93, 1863-5)

hilin / hilin(M139, 2537-

6)

himmet / himmẹt(M111, 2124-3; 111, 2125-4)

içer / içer(M134, 2467-9)

içgü / iç̧ü(M132, 24399)

içgüçi / içgüçi(M109, 2106-16)

için / içinin(M125, 2336-7) içinde / içinde(M102, 1999-16)

içine / içine(M117, 2216$15 ; 117,2216-15)$ içme / içme(M109, 20965) 
içmez / içmes(M108, 2091-16)

içse / içse(M103, 2003-3; 109, 2096-5; 109, 2101$10 ; 109,2103-12)$

içür / içür(M106, 2053-9)

iḍi / iḍii(M101, 1973-3)

iḍim / iḍim(M87, 1783-

13)

igine / igine(M110, 2109-

2)

igler / igler(M100, 1969-

15)

ikigü / ikigï(M101, 1972-

2 ; 101, 1973-3; 79, 1663-

16)

ikigün / ikigün(M133, 2456-13)

ikinçi / ikinçi(M136, 2504-18)

ikinçi / ikinçi(M124, 2325-11; 126, 2357-10; 126, 2357-16)

ikindin / ikindin(M128, 2374-2)

ilig / ịlịg (M25. başl1k)

ilig / ịlig(M114, 2169-2)

ilig / ilig (M , 1587-12; 1588-13;94, 16. başl1k;94, 1889-17;, 1586-11;100, 1969-15;105, 2037-6;107, 2068-8;107, 2068-8;113, 2154-3;118, 2238-11;120, 2269-12;135, 2489$15 ; 137, \quad 2507-3 ; 138$, 2525-6;139, 2546-15;76, 1613-7;77, 1633-12;78, 1641-6;78, 1644-9;81, 1684-7;86, 1764-9;86, $1767-12 ; 89, \quad 1805-3 ; 91$, 1845-17)

ilig / jilig (M , 1589-14; , 1582-6;123, ;77, 1623$2 ; 79, \quad 5$. başlık;80, 1. başlık;80, 16. başlık;88, 4 . başl1k;89, 14. başl1k;90, 17. başlık;92, 2. başl1k;95, 7. başlık;96, 10. başlık;98, 12. başlık;99, 2.başlık; , 1585-10; , 1590-15; ,
1601-12;107, 2071$12 ; 112, \quad 2142-6 ; 112$, 2146-11;113, 2164$12 ; 114, \quad 2174-7 ; 114$, 2180-14;118, 2240$13 ; 120, \quad 2260-2 ; 120$, 2265-7;131, 2426-9;131, 2429-13;131, 2430$14 ; 132, \quad 2434-2 ; 132$, 2435-4;136, 2503-17;137, 2509-5;138, 2526-7;76, 1607-1;76, 1612-6;78, 1642-7;78, 1645-10;79, 1654-4;79, 1655-6;79, 1656-7;80, 1666-4;80, 1677-17;81, 1679-3;82, 1692-1;83, 1716-9;83, 1721-15;85, 1749-10;85, 1752-13;86, 1772-17;87, 1774-2;87, 1782-12;87, 1783-13;87, 1784-14;88, 1796-11;88, 1801-16;89, 1805-3;89, 1815-15;91, 1832-1;92, 1848-3;92, 1853-9;95, 1894-8;96, 1903-3;96, 1905-6;96, 1907-8;96, 1909-11;97, 1917-4;97, 1918-6;97, 1920-8;97, 1921-10;98, 1930-4;98, 1936-11;98, 1937-13;99, 1948-9; 1590-16; 76, 1607-1; 80, 1665-2; 96, 1908-9)

ilig /ilig(M114, 2175-5; 114, 8. başlık; 130, 24176 ; 131, 2426-9; 88, 17915; 93, 1872-15)

iligke / ịligke (M88, 10. başlık)

iligke / iligke (M120, 30. başlık; 96, 5. başlık) iligke / jligke (M81, 2. başlık; 9. başlık; 95, 3. başlık)

iligke / iligke (M , 15815;11. başlik;79, 10. başlık;80, 3. başlık;89, 17. başlık;91, 4. başlık;95, 10. başlık;96, 13. başlık;97, 5. başlık;98, 3. başlık;115,
2193-13;118, 2242-16;83, 1719-12)

ilig-ke / ilig-ke (M92, 5. başlık)

iligke / ilig-ke(M85, 1753-14; 94, 1886-12)

iligni / illigni(M89, 18042)

ilin / inlin(M103, 2016-17; 104, 2017-1; 104, 202410 ; 87, 1773-1; 94, 188815)

ilin / iling(M1 14, 2179-13) iltmez / iltmez(M136, 2492-5)

iltse / iltse(M120, 226710)

inç / inç(M104, 2022-7; 138, 2528-11; 99, 1948-9) inçin / inçin(M87, 17742)

inçke / inçke(M114, 2180-14; 87, 1782-12)

inçlik / inçlikk(M112, 2144-8)

inçlik / inçlik(M112, 2143-7; 114, 2173-6)

inç-siz / inç-siz(M93, 1871-14)

ir / ir (M97, 28. başlık; 135, 2477-2)

iriglendi / iriglendi(M , 1586-11)

irilmes / irilmes(M103, 2005-5)

isig / isig(M135, 2479-4) isig / isiz(M130, 2405-2)

isinse / isinse(M114, 2179-13)

isitse / insitse(M139, 254716)

isitür / isitür(M122, 229510)

ịsitür / isitür(M111, 21232) isiz / isiz(M119, 22485;119, 2255-14;119, 2257-16;120, 2259-1;78, 1641-6;88, 1790-3;97, 1922-11) 
isizig / issizig(M119,

isizke / issizke(M111, 2131-11; 119, 2257-16)

isizler /isizler(M119, 2248-5)

isizlerke / isizlerke(M122, 2299-14; 123, 2303-2)

isizni / isizni(M117, 2214-2)

iş / iş (M98, 1939-15; 82, 1694-3)

işi / issi(M101, 1984-17; 119, 2258-17; 80, 1670-8; 98, 1935-10)

işig / işigg(M102, 1986-1)

işig / işig(M102, 1990-5; 118, 2236-9; 130, 2408-6; 134, 2471-13; 134, 2471$13 ; 137,2506-2)$

işim / işim(M78, 1645-10; 93, 1862-4; 76, 1615-9) işin / iş̧ূn(M104, 2027-13; 83, 1721-15; 97, 1924-13; 98, 1931-5)

işin / işin(M102, 1989-4; 116, 2211-16; 120, 226710; 99, 1952-13)

işin / issing (M134, 2468-10) işine / iş̧ine(M102, 19883)

işler / işler(M102, 199815 ; 102, 1998-15; 109, 2102-11)

işlese / işlese(M102, 1989-4)

işni / issnni(M116, 2202-7; 98, 1936-11)

itigli / itigli(M93, 1862-4)

itiglig / itiglik(M125, 2340-12)

itig-siz / itig-siz(M85, 1753-14)

itildi / itijldi(M86, 177217)

itilse / itịlse(M97, 192514) itilse / intilse(M107, 20688) itse / itse(M114, 2179-13; 126, 2344-1)

ivinme / ivininme(M127, 2359-1)

iv́eklik / iv́ekligk(M108, 2078-1)

iv́eklik / iv́eklik(M106, 2061-16)

kereklig / kereklig(M96, 1904-4)

kesgil / kẹsgịl(M127, 2363-5)

kiç / kị̧c(M105, 2036-5)

kiç / kịç (M123, ; 104, 2031-17; 135, 2489-15)

kiçe / kịçe(M79, 1562-2)

kiçe / kịçe(M127, 2361-3; 127, 2361-3; 139, 2533-1; 139, 2536-5)

kiçig / kịçig(M102, 199410 ; 134, 2475-17; 82, 1695-4; 88, 1793-7)

kiçig / kịçịg(M110, 211612; 86, 1768-13; 90, 1823-7; 92, 1851-7; 92, 1851-7)

kiçig / kịçịi(M93, 187114)

kiçig / kịçig(M135, 2477 2)

kiçig / kịçig(M136, 24935)

kiçig / kịçig(M107, 207011 ; 128, 2373-1; 89, 1814-3; 97, 1922-11)

kiçigde (Mn) / kịçigde(Mn) (M78, 164813)

kiçigde / kịçigde(M90, 1822-6)

kiçig-de / kịçig-de(M98, 1941-17)

kiçigke / kịçigke(M88, 1793-7)

kiçiglik / kịçiglik(M82, 1702-12; 82, 1703-13)

kiçiglikte

kiçiglikte(M77, 1628-8)

kidin / kịdin(M80, 1672-

10) kim / kim(M139, 2534-2; 139, 2543-13)

kimde / kịmde(M118, 2238-11)

kimin / kịmin(M117, 2213-1)

kimin / kịmign(M80, 16708)

kimin / kimin(M82, 16998) kimin / kiming(M82, 16987; 82, 1702-12)

kimke / kimke(M101, 1983-15)

kirür / kịrür(M104, 20238)

kişedi / kişedi(M91, 1838-9)

kişen / kịşen(M91, 18377)

kişi / kịşi (M , 1580-3; , 1598-8; , 1599-9; , 160010)

kişi / kị̧si(M100, 196713;110, 2109-2;110, 2119-15;113, 2154-3;115, 2196-16;116, 2199-3;116, 2201-5;116, 2201-6;116, 2203-8;117, 2214-2;117, 2215-14;118, 2232-5;120, $2259-1 ; 122, \quad 2287-2 ; 123$, 2305-6;123, 2308-10;123, 2308-10;124, 2316-1;124, 2325-11;125, 2334-5;126, 2350-8;132, 2438-8;132, 2439-9;133, 2445-1;134, 2460-1;139, 2538-7;77, 1623-3;89, 1816-16)

kişi / kişi(M , 1595-5; , 1598-8;101, 1975-7;102, 1986-1;102, 1992-7;103, 2001-1;103, 2003-3;103, 2004-4;105, 2039-9;105, 2040-10;105, 204212;106, 2045-1;107, 2075-16;108, 208812;108, 2090-15;109, 2099-8;115, 2189-9;115, 2191-11;115, 2192$12 ; 115, \quad 2195-15 ; 117$, 
$2220-9 ; 120, \quad 2266-9 ; 122$, 2293-8; 122, 2295-10;124, $2319-5 ; 130, \quad 2410-8 ; 132$, 2442-12;133, 2452-9;134, 2463-14;134, 2463$14 ; 134, \quad 2467-9 ; 134$, 2470-12;135, 2477-2;135, 2485-10;136, 2493-5;76, 1616-10;76, 1616-10;76, $1617-11 ; 76, \quad 1618-12 ; 77$, $1627-7 ; 77, \quad 1633-12 ; 77$, $1637-16 ; 77, \quad 1637-16 ; 78$, $1639-3 ; 78, \quad 1647-12 ; 81$, 1683-7;81, 1689-14;81, 1689-14;82, 1699-8;82, 1706-16;83, 1724-18;84, 1731-7;84, 1739-16;88, 1788-1;88, 1799-14;89, 1807-5;90, 1824-8;90, 1825-9;90, 1827-11;91, 1843-14;91, 1845-17;93, 1860-2;95, 1900-15;97, 1914-1;98, 1935-10;98, 1938-14;99, 1943-2;99, 1945-5; , 1596-7; 104, 2030-16; 77, 1629-9; 84, 1727-3)

kişide / kịşide(M116, 2199-3;116, 2201-5;116, 2201-6;116, 2205-10;133, 2457-14)

kişide / kişide(M103, 2005-5; 80, 1669-7; 84, 1731-7; 90, 1830-15)

kişide / kişike(M84, 1725-1)

kişidin / kị̧sidin(M111, 2122-1)

kişig / kịşig(M107, 207718;118, 2236-9;119, 2251-8;133, 2445-1;137, 2506-2;142, 2577-1)

kişig / kissig(M102, 19905; 110, 2120-16; 83, 1718-11; 85, 1751-12; 87, 1776-5; 89, 1806-14)

kişike / kịşike(M , 15967; 130, 2405-2; 139, 2541-11; 82, 1703-13) kişike / kişike(M102, 1995-11;105, 204010;107, 2066-6;118, 2229-12;135, 2476-11;76, 1619-13;77, 1632-12;79, 1659-12;80, 1665-2;83, 1714-7;91, 1835-5;91, 1837-7;99, 1943-3;99, 1946-7)

kişiler / kịşiler(M116, 2197-1; 118, 2230-3; 119, 2256-15; 121, 2284-13; 129, 2394-6; 134, 247214)

kişiler / kişiler(M101, 1975-7;102, 1990-5;105, 2039-9;111, 2123-2;115, 2194-14;130, 2408-6;84, 1739-16;85, 1749-10;99, 1946-7)

kişi-ler / kịşi-ler(M121, 2283-12)

kişilerde / kişsilerde(M79, 1658-11)

kişilerke / kişilierke(M92, 1854-11)

kişilik / kịşilik(M , 15999; 123, 2308-10; 123, 2308-10)

kişilik / kịşilikk (M , 15999; 124, 2321-7)

kişilik / kisşilik(M , 15967; 105, 2040-10; 135, 2476-11; 77, 1635-15; 79, 1664-17; 81, 1691-17)

kişilik / kisşilik(M , 160010; 77, 1634-14; 81, 1690-16; 81, 1690-16; 99, 1945-5)

kişilik / kiş̧̧ilik(M78, 1636-1)

kişilik / kisşilik(M81, 1690-16)

kişilik / kı̣şi-lik(M , 160010)

kişilikni / kịşilikni(M , 1596-7)

kişinin / kịşinin(M95, 1901-17; 99, 1954-15) kişisi / kiş̧isi(M94, 188713)

kişisin / kişisin(M86, 1770-15)

kit(Mt)i / kịt(Mt)i (M114, 2172-5)

mẹnịlig / mẹỵlig (M101, 5. başlık)

meniz / mẹniz(M128, 2384-12)

negü / nịgü(M78, 1638-2) nejin / nigin(M121, 2278-6)

nigü / nịgü(M117, 222616 ; 138, 2527-9; 76, 16082)

nigü / nigü (M85, başlık;88, 1795-9; 1583$7 ; 100,1962-8 ; 102$, 19927;104, 2019-3;104, 203117;106, 2052-8;108, 2088-12;109, 2095-4;109, 2100-9;110, 2117-13;112, 2141-5;113, 2153-1;113, 2159-8;113, 2167-17;115, 2196-16;116, 2204-9;117, 2214-2;117, 2225-15;118, 2228-1;118, 2231-4;118, 2243-17;120, 2266-9;121, 2287-16;123, 2306-6;127, 2367-10;128, 2379-7;131, 2424-7;133, 2455-12;135, 2477-2;137, 2513-9;138, 10. başl1k;138, 2521-1;76, 1616-10;76, 1620-15;77, 1624-4;80, 1673-11;81, 1689-14;83, 1724-18;85, 1742-2;85, 1753-14;85, 1754-15;91, 1833-2;91, 1834-3;91, 1843-14;94, 1880-6;95, 1895-9;96, 1913-16;97, 1924-13;99, 1945-5;99, 1955-16) nịgüke / nigüke(M85, 1756-17)

nigüni / nigüni(M90, 1819-3)

nip / nị (M124, 2325-11) nin-ke / nịkke(M116, 2200-14) 
nişạnı / nịşanı(M117, 2224-13; 95, 1894-8)

ögdülmiş / ögdülmiş (M98, 3. b aşlik)

ögdülmişig / ögdülmịşig (M94, 1889-17; 83, 17169 ; $85,1751-12 ; 86,1764-$

9)

ögdülmişig
ögdülmişig(M78, 1641-6)
ögdülmişig
ögdülmişig(M76, 1612-6)
öteyin / öteỵ̣n(M94,
1877-2)

senindin / sẹnindin(M138, 2526-8)

seninsiz / sẹninsiz(M92, 1859-16; 93, 1860-2)

sẹrim-lig / serim$\operatorname{lig}(\mathrm{M} 135,2480-5)$

serı̣m-lüg / sirimlüg(M93, 1867-9)

sev́inçin / sẹvinçỉn(M101, 1977-9; 137, 2512-8)

sev́inçin / sẹvini̧çin(M112, 2145-10)

sevínçmü / sev́inçmü (M , 1584-8)

sev́inçlig

sẹvininçlig(M1 12, 2145-9)

sikirtse / sịkirtse(M137, 2508-4)

silig / sịlig(M107, 207213;108, 2086-10;116, 2197-1;133, 2446-2; 103, 2006-6)

silig / silig(M132, 2444$15 ; 92,1852-8)$

silig / sịlig(M93, 1866-8)

siliglik / siliglik(M99, 1951-12)

siringil / siringịl(M128, 2379-7)

siringü / siringü(M121, 2285-14)

siz / sigz(M1 19, 2247-4)

siziksiz / siziksiz(M115, 2182-1)

siziksiz / siziksiz(M120, 2270-13) sözin / sözịn(M99, 1943-

2)

şa 'ir / şa 'ịr(M107, 2065-

4; 107, 2065-4; 135, 2486-11)

şi ' $\mathrm{r} / \mathrm{ş̣i} \mathrm{'} \mathrm{r}$ (M138, 2. başlık;102, 8. başlık;105, 17. başlık;107, 5 . başlık;110, 7. başlık;117, 3. başlık;119, 12. başl1k;122, 1. başlık;123, 8. başlik;127, 12 . başlık;128, 8. başlık;130, 5. başlik;135, 12 . başlık;136, 3. başlık;142, 3. başlık;87, 9. başlık;89, $11 . \quad$ başlik;91, 16.başl1k;95, 16. başlık; 108, 2089-14; 113, 2. başlık; 99, 17. başlık; 99, 6. başl1k)

teg / tig (M114, 15. başlik)

tẹy / tig(M78, 1650-16)

tẹy / tig(M78, 1650-16; 78, 1658-17)

teneşçi / tịneşçi(M119, 2256-15)

teninçe / tẹninçe(M108, 2090-15)

tensiz / tẹnsizz(M109, 2107-17; 103, 2006-6; 109, 2102-11)

tigey / tigey(M109, 210312)

tigü / tigü(M130, 2407-4;

84, 1730-6; 84, 1732-8)

tigüçi / tịgüçi(M122, 2293-8)

tikgü / tịkgü(M113, 2165-

13)

tikti / tikti(M86, 1765-10)

til / til(M113, 2158-7)

tildin / tịldin(M97, 1916-

3)

tile / tile(M125, 2339-11)

tilek / tịlek (M94, ; 94, 1882-8)

tilekçe / tịlekçe(M118, 2240-13) tileki / tịleki(M76, 1609-

3)

tilekin / tillekin(M107, 2076-17; 130, 2416-15)

tilekke / tịlekke(M90,

1821-5)

tilek-ke / tillek-ke(M93,

1867-9)

tileme / tilleme(M125, 2339-11)

tilemiş / tịlemiş(M78, 1645-10)

tiler / tiller(M104, 202511)

tilese / tilese(M101, 1979$11 ; 121, \quad 2279-7 ; 124$, 2320-6;124, 2320-6;124, 2322-8;77, 1622-1;85, 1744-4)

tili / tili(M103, 201010;105, 2041-11;118, 2235-8;137, 2515-11;90, 1817-1;94, 1880-6)

tilig / tilig(M , 1590-15)

tịlig / tịlig(M108, 208610)

tilig / tiligg(M92, 1846-1)

tilim / tịlim(M125, 2343-

17)

tilin / tilin(M138, 2522-3; 139 , 2547-16; 76, 1618$12 ; 82,1696-5)$

tilin / tilin(M107, 207011 ; 127, 2363-5; 132, 2435-4; 135, 2480-5)

tilinde / tillinde(M137, 2506-1)

tilr / tiller(M101, 1985-18) tilv́e / tịlv́e(M109, 20998)

timegü / timegü(M90, 1831-16)

timiş / tịmiş(M125, 2334-

5) timiş / timịş(M125, 2337-

8)

timlenür /timlenür(M134, 2465-6)

tip / tip(M105, 2032-2) 
tir / tịr (M85, başlik; , 1594-4;104, 2019-3;105, 2040-10;106, 2052-8;108, 2088-12;109, 2095-4;109, 2100-9;110, 2117-13;113, 2153-1;113, 2167-17;115, 2196-16;117, 2214-2;121, 2287-16;123, 2306-6; 127, 2365-7; 127, 2367-10;128, $2379-7 ; 131, \quad 2424-7 ; 135$, $2477-2 ; 137, \quad 2513-9 ; 138$, $2521-1 ; 76, \quad 1620-15 ; 85$, 1754-15;94, 1880-6;96, 1913-16;99, 1945-5;99, 1955-16; 100, 1962-8; 102, 1992-7; 118, 2231-4; 124, 2319-5; 76, 1616-10; 80, 1673-11; 81, 1689-14) tiren / tiren(M106, 2061$16 ; 128,2378-6)$

tirer / tirer(M84, 1732-8; 95, 1890-1)

tirgüçi / tịrgüçi(M76, 1620-15)

tirig / tijig(M133, 2450-6; 135, 2478-3)

tiriglik / tiriglik(M103, 2013-14;113, 2162$12 ; 113, \quad 2162-12 ; 124$, 2318-4;124, 2320-6)

tiriglikte / tiriglikte(M83, 1724-18)

tiriglik-te / tiriglikte(M142, 2577-1)

tiril / tịril(M104, 2022-7; 112, 2145-10)

tirildi / tịijuldi(M87, 178717)

tirilgey / tirilgey(M120, 2264-6)

tirilgil /tirilgil(M138, 2528-11)

tirilse / tirilse(M101, 1976-8;105, 2038-8; 88, 1800-15)

tirilsü / tịrilsü(M , 1585$10 ; 132,2435-4)$

tirip / tirip(M139, 2537-6; 80, 1675-14) tirlür / tịrlür(M106, 2051$7 ; 77,1632-12$ )

tirmese / tirmese (M121, 2278-6)

tise / tise(M108, 2081-5)

tişin / tiş̧in(M128, 2377-5;

128, 2377-5)

titim / tịtim(M100, 1961-

7)

titim / tịtim(M105, 2043-

13)

titim-lüg / tịtim-

lüg(M124, 2328-14)

tịtir / tịtịr(M123, 2312-14)

titrü / tịtrü(M101, 1984-

17)

tiyü / tịyü(M95, 1895-9)

tizginür / tỉzginür(M84, 1733-9)

üsterigli / üsterigli(M116, 2205-10)

vẹzir / vẹzịr(M115, 2183-

2)

yetilmiş / yẹtilmiş(M86,

1758-2)

yetilmiş / yẹtịlmiş(M83,

1724-18)

yẹtim / yẹtịm(M136,

2498-10)

yidi / yidi(M120, 2264-6;

129, 2395-7)

yig / yị(M102, 1998-15)

yig / yig(M132, 2443-14)

yigey / yịgey(M120,

2264-6)

yigitler / yigitler(M128,

2373-1)

yigli / yigli(M106, 2052-

8)

yiglikin / yiglikinn(M98, 1932-6)

yịgrek / yigrek(M98,

1936-11)

yigü / tịgü(M85, 1743-3)

yigü / yịgü(M131, 2424-

7; 84, 1732-8)

yigü / yigü(M101, 1982-

14)

yigüçi / yịgüçi (M80, 1675-14) yilig / yilig(M116, 2198-

2)

yilip / yillip(M87, 1780-

10)

yime / yịme(M105, 2043-

13 ; 117, 2213-1; 125, 2337-8; 137, 2514-10; 85, 1746-7; 86, 1762-7)

yime / yime(M106, 2059-

14; 132, 2434-2; 78, 1639-3; 82, 1701-10; 88, 1794-8)

yimez / yịmez(M84, 1738-15)

yimez / yimez(M104, 2027-13; 104, 2030-16; $112,2144-8)$

yimi / yịmi(M136, 24968)

yimiş / yimiş̧s(M78, 165817)

yimişsiz / yịmişsiz(M133, 2455-12; 133, 2455-12)

yinçke / yịnçke(M135, 2490-17)

yine / yịme(M118, 2237-

10)

yịnik / yịnik(M108, 20781)

yir / yịr(M , 1601-12; 133, 2456-13;139, 25487; 84, 1736-12;118, 2233$6 ; 137,2518-15)$

yir / yir(M107, 2076-17; 112, 2142-6; 113, 2156-5; $121,2278-6$; 122, 2296$11 ; 126,2355-13 ; 84$, 1735-11)

yirgürür / yịrgürür(M107, 2077-18)

yirke / yịrke(M77, 16244)

yise / yise(M105, 20322; 133, 2456-13; 98, 1929-2)

yise / yịse (M111, 213617 ; 101, 1976-8; 102, 1998-15; 103, 2003-3; 116, 2200-14; 98, 1929-2) 
yiti / yịti(M127, 2369-14; 95, 1890-1)

yiti-lik / yịti-lik(M124, 2328-14)

yitür / yịtür(M106, 2053-

9; 129, 2403-7)

yitür / yịtür(M124, 2320-

6)

yitürdüm / yịtürdüm(M76,

1613-7; 81, 1685-9)

yitürse / yitürse(M116,

2198-2; 121, 2280-9)

yiyümedi

yiyümedi(M104, 2031-

17)

yüreklig / yüreklig(M105, 2043-13; 105, 204414;106, 2045-1;106, 2045-1;121, 2282-11;121, 2285-14;122, 2293-8;124, 2326-12; 114, 2168-1)

yüzin / yüzinn(M108, 2084-8)

içmi / içmi(M109, 20987)

\section{1. 5. /o/ Ünlüsü}

4 örnekte /o/ ünlüsünün yazımıyl ilgili farklılık tespit edilmiştir.

bolunsa / bọlunsa(M137, 2507-3)

bolur / bọlur(M82, 1699-

8)

tolum / tọlum(M121, 2277-5)

yolı / yọlı(M85, 1756-17)

\section{1. 6. /ö/ Ünlüsü}

Örnek tespit edilememiştir.

\section{1. 7. /u/ Ünlüsü}

42 örnekte /u/ ünlüsünün yazımıyla ilgili farklılık tespit edilmiş̧ir. aytur / aytụr(M79, 16567)

buḍunka

bụdunḳa(M100, 1961-7;

100, 1963-9; 100, 1964-

10)

bulġanuk

bụlġanuḳ(M92, 1856-13)

bulġaşur

bụlġaşur(M125, 2336-7)

bulgus1 / bụlġus1(M85,

1744-5)

bulmasa / bụlmasa(M127,

2362-4)

bulun / bụlun(M107, 2066-6; 128, 2388-18; 129, 2402-16)

bụlur / bulur(M106, 20517)

bulur / bụlur(M107, 207617; 111, 2135-16; 113, 2166-16; 135, 2478-3; 76, 1617-11; 94, 1884-10)

buzuldı / bụzuldı(M112, 2137-1)

\section{buzulmaz}

bụzulmaz(M105, 2036-5)

kulnung / kụlnun(M97, 1919-7)

ḳurg் ～/ kụrg்u(M102, 1997-14)

ḳurug / ḳurụgg(M77, 1626-

6)

kutlug / kụtlugig(M101, 1973-3)

oldurup / oldurụp(M76, 1613-7)

sụ'ali / su'ali (M89, 14. başlık;80, 16. başlık;79, 5 . başlik;90, 17. başlık)sụ'ali/ su'ali(M80, 1. başlık; 99, 2 . başlık;114, 8. başlık;94, 16. başlık;88, 4. başlık;92, 2. başlık) sụrẹti / sureti (M) suv́ / sụv́(M105, 2032$1 ; 108,2085-9 ; 121,2278-$ 6;126, 2349-7;134, 2467$9 ; 84,1735-11)$ suv́1 / sụv́1(M103, 2007-7; 103, 2007-7; 89, 1808-6)

suv́lanur

sụv́lanur(M116，2207-12; 116, 2207-12)

suv́un / sụvun(M110, 2108-1)

turug / tụrugig(M139, 25487)

turur / tụrur(M101, 198214;102, 1995-11;103, 2015-16;105, 2032-1;105, 2032-1;111, 2132-12;113, 2156-5;117, 2224-13;121, 2286-15;126, $2357-$ 10;126, 2357-16;126, 2357-17;129, 2391-3;135, 2484-9;136, 2492-4;80, 1668-6;91, 1834-3;91, 1836-6;99, 1953-14)

tusuldı / tụsuldı(M79, 1653-3)

tusulsa / tụsulsa(M132, 2437-6)

tusulup / tụsulup(M76, 1619-14)

tususı / tụsusi(M131, 2421-3)

tutund1 / tụtundı(M82, 1696-7)

ulur / ụlur(M106, 2059-

14)

uv́ut / ụv́ut(M116, 2207-

12)

uv́ut1 / ụv́ut1(M122, 2289-

4)

uv́utlug / ụv́utlugi(M116, 2204-9)

uv́utlug / ụv́utluġ(M133, 2445-1)

uv́utsuz / ụv́utsuz(M116, 2203-8; 116, 220611;116, 2206-11)

yulug / yụlug (M , 160314)

yulugilap

yụlug̉lap(M121, 2281-10) 


\section{1. 8. /ü/ Ünlüsü}

5 örnekte /ü/ ünlüsünün yazımıyla ilgili farklılık tespit edilmiştir.

küv́ense / kụ̈vense(M132, 2433-1)

mürụ̈vvẹt

mürüvvẹt(M111, 2125-4;

111, 2124-3)

tüpi / tụ̈pi(M113, 2159-8;

113, 2159-8)

ülüg / ụ̈lüg(M90, 1829-

14)

\section{2. Ünsüzler}

\section{2. 1. /d/ Ünsüzü}

1 örnekte /d/ ünsüzünün yazımıyla ilgili farklılık tespit edilmiştir.

aydur / aytur(M118, 2228-1)

\section{2. 2. /z/ Ünsüzü}

2 örnekte /z/ ünsüzünün yazımıyla ilgili farklılık tespit edilmiştir.

içmez / iç̧mes(M108, 2091-16)

uḳz-a / uḳs-a(M85, 1754-

15) 


\section{SONUÇ}

3. 1. Ünlülerin yazımıyla ilgili farklılıklar en çok /i/ ünlüsünün yazımıyla ilgilidir. Çoğunlukla /i/ ünlüsünün eksik yazımla işaretlenmesi söz konusudur. Bu örnekler için RRA tarafindan ayrıcı bir işaret kullanılmamıştır. Örneklerin çoğu kelime içi yazımla ilgilidir.

Az sayıda örnekte ise /i/ ünlüsünün işaretlenmemesi söz konusudur. Bu örnekler için de yine RRA tarafından ayırıcı bir işaretin kullanılmadığı görülür.

3. 2. /a/ ünlüsünün yazımıyla ilgili olarak ortaya çıkan farklılıklar /a/ ünlüsünün işaretlenmediği örneklere aittir. Bu örnekler için RRA tarafından genellikle ayırıcı işaret kullanılmadığı görülür. Örneklerin tamamı kelime içi yazımla ilgilidir.

3. 3. /e/ ünlüsünün yazımıyla ilgili olarak ortaya çıkan farklılıklar /e/ ünlüsünün işaretlenmediği örneklere aittir. Bu örnekler için RRA tarafından genellikle ayırıcı işaret kullanılmadığı görülür. Örneklerin tamamı kelime içi yazımla ilgilidir.

3. 4. /1/ ünlüsünün yazımıyla ilgili ortaya çıkan farklılıklar genellikle /1/ ünlüsünün eksik yazımıyla ilgilidir. Arap harfli metinlerde kelime içinde "iki noktalı y" ile işaretlenen /1/, Fergana nüshasında çoğunlukla "noktasız" olarak işaretlenmiştir. Örneklerin çoğunluğu kelime içine ait olmakla birlikte, bir örnekte kelime başında da bu duruma rastlandığı görülür. RRA tarafından eksik yazımla gösterilen /ı/ için ayırıcı işaret kullanılmadığı görülür.

Az sayıda örnekte ise yazımda gösterilmeyen /1/ harfinin RRA tarafından ayrıcı bir işaretle gösterilmediği tespit edilmiştir.

3. 5. /i/ ünlüsünün yazımıyla ilgili ortaya çıkan farklılıklar genellikle /i/ ünlüsünün eksik yazımıyla ilgilidir. Arap harfli metinlerde kelime başında "elif ve iki noktalı y" ile işaretlenen /i/ , Fergana nüshasında çoğunlukla "noktasız" olarak işaretlenmiştir. Örneklerin çoğunluğu kelime başına ait olmakla birlikte, az sayılamayacak örnekte kelime içinde de bu 
duruma rastlandığı görülür. RRA tarafından eksik yazımla gösterilen /i/ için ayırıcı işaret kullanılmadığı görülür.

3. 6. /o/ ünlüsünün yazımıyla ilgili olarak ortaya çıkan farklılıklar /o/ ünlüsünün işaretlenmediği örneklere aittir. Bu örnekler için RRA tarafından genellikle ayırıcı işaret kullanılmadığı görülür. Örneklerin tamamı kelime içi yazımla ilgilidir.

3. 7. /ö/ ünlüsü için farklı örnek tespit edilmemiştir.

3. 8. /u/ ünlüsünün yazımılla ilgili olarak ortaya çıkan farkllılklar /u/ ünlüsünün işaretlenmediği örneklere aittir. Bu örnekler için RRA tarafından genellikle ayırıcı işaret kullanılmadığı görülür. Örneklerin çoğunluğu kelime içi yazımla ilgili olmakla birlikte, 5 örnekte kelime başında da bu duruma rastlandığı görülür.

3. 9. /ü/ ünlüsünün yazımıyla ilgili olarak ortaya çıkan farklılıklar /ü/ ünlüsünün işaretlenmediği örneklere aittir. Bu örnekler için RRA tarafından genellikle ayırıcı işaret kullanılmadığı görülür. Örneklerin çoğunluğu kelime içi yazımla ilgili olmakla birlikte, 1 örnekte kelime başında da bu duruma rastlandığı görülür.

3. 10. /d/ ünsüzü ile ilgili tek örnek tespit edilmiş olup, örnek kelime içi /d/ sesine aittir. RRA tarafından ötümlü biçimiyle yazımda gösterilen ünsüz, nüshada /t/ ile yazılmıştır.

3. 11. /z/ ünsüzünün yazımıyla ilgili tek örnek tespit edilmiş olup, örnekler kelime sonu yazımıyla ilgilidir. RRA tarafından ötümlü biçimiyle yazımda gösterilen ünsüz, nüshada /s/ biçimindedir.

3. 12. Arap harfli bu nüshada, kelime içinde /i/ yazımı için " $y$ " nin " noktasız" işaretlenmesi, nüshanın büyük bir bölümünde görülen bir durumdur. Diğer yandan, müstensihin "noktalı" yazımlarını da görmekteyiz. RRA tarafından bu "noktasız" yazımlar ayırıcı işaretle 
verilmemiş ve eksik yazım olarak kabul edilmemiştir. Belki de RRA bu durumun, müstensihin hatası olduğunu düşünmüştür; fakat bu kadar yaygın kullanımı olan bir yazım özelliğini müstensih hatası olarak kabul etmek doğru olmayabilir. Noktalı yazım geleneği daha yeni bir devre aittir. Belki de müstensih, bir yazım geleneğini nüshaya yansıtmak istemiş olabilir.

\section{KISALTMA VE İŞARETLER}

\section{Kisaltmalar}

RRA: Reşit Rahmeti Arat Kutadgu Bilig Metin Yayını

M: Kutadgu Bilig Mısır Nüshası

\section{İşaretler}

ạ: Arap harfli yazımda işaretlenmeyen /a/

ẹ : Arap harfli yazımda işaretlenmeyen /e/

1 : Arap harfli yazımda işaretlenmeyen /1/

1: Arap harfli yazımda, eksik yazımla işaretlenen /1/

i : Arap harfli yazımda işaretlenmeyen /i/

$\mathrm{i}$ : Arap harfli yazımda, eksik yazımla işaretlenen /i/

o : Arap harfli yazımda işaretlenmeyen /o/

ụ : Arap harfli yazımda işaretlenmeyen /u/

\section{KAYNAKÇA}

Arat, R. R. 2007. Kutadgu Bilig I Metin. Ankara: Türk Dil Kurumu Yayınları.

Kutadgu Bilig Tıpkıbasım III Mısır Nüshası. 1943. İstanbul: Türk Dil Kurumu Yayınları.

Üşenmez, E. 2013. Kutadgu Bilig (Nemengan/ Fergana/ Özbekistan nüshası tıpkıbasım). İstanbul: Akademik Kitaplar.

Üşenmez, E. 2014. Kutadgu Bilig (Herat, Viyana- Avusturya- nüshası tıpkıbasım). İstanbul: Akademik Kitaplar.

Üşenmez, E., Uçar, E. 2014. Kutadgu Bilig (Kahire nüshası tıpkıbasım). İstanbul: Akademik Kitaplar. 